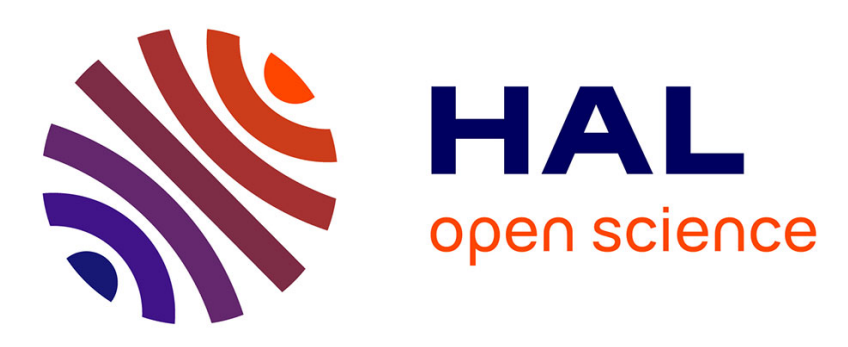

\title{
Mercury Sulfide Dimorphism in Thioarsenate Glasses
}

Mohammad Kassem, Anton Sokolov, Arnaud C Cuisset, Takeshi Usuki, Sohayb Khaoulani, Pascal Masselin, David Le Coq, M. Feygenson, C. J. Benmore, Alex C Hannon, et al.

\section{- To cite this version:}

Mohammad Kassem, Anton Sokolov, Arnaud C Cuisset, Takeshi Usuki, Sohayb Khaoulani, et al.. Mercury Sulfide Dimorphism in Thioarsenate Glasses. Journal of Physical Chemistry B, 2016, 120 (23), pp.5278 - 5290. 10.1021/acs.jpcb.6b03382 . hal-01426924

\section{HAL Id: hal-01426924 https://hal.science/hal-01426924}

Submitted on 5 Jan 2017

HAL is a multi-disciplinary open access archive for the deposit and dissemination of scientific research documents, whether they are published or not. The documents may come from teaching and research institutions in France or abroad, or from public or private research centers.
L'archive ouverte pluridisciplinaire HAL, est destinée au dépôt et à la diffusion de documents scientifiques de niveau recherche, publiés ou non, émanant des établissements d'enseignement et de recherche français ou étrangers, des laboratoires publics ou privés. 


\section{Article}

Mercury Sulfide Dimorphism in Thioarsenate Glasses

Mohammad Kassem, Anton Sokolov, Arnaud Cuisset, Takeshi Usuki, Sohayb Khaoulani, Pascal Masselin, David Le Coq, Joerg C. Neuefeind, Mikhail Feygenson, Alex C Hannon, Chris J. Benmore, and Eugene Bychkov

J. Phys. Chem. B, Just Accepted Manuscript • Publication Date (Web): 23 May 2016

Downloaded from http://pubs.acs.org on May 23, 2016

\section{Just Accepted}

"Just Accepted" manuscripts have been peer-reviewed and accepted for publication. They are posted online prior to technical editing, formatting for publication and author proofing. The American Chemical Society provides "Just Accepted" as a free service to the research community to expedite the dissemination of scientific material as soon as possible after acceptance. "Just Accepted" manuscripts appear in full in PDF format accompanied by an HTML abstract. "Just Accepted" manuscripts have been fully peer reviewed, but should not be considered the official version of record. They are accessible to all readers and citable by the Digital Object Identifier (DOI@). "Just Accepted" is an optional service offered to authors. Therefore, the "Just Accepted" Web site may not include all articles that will be published in the journal. After a manuscript is technically edited and formatted, it will be removed from the "Just Accepted" Web site and published as an ASAP article. Note that technical editing may introduce minor changes to the manuscript text and/or graphics which could affect content, and all legal disclaimers and ethical guidelines that apply to the journal pertain. ACS cannot be held responsible for errors or consequences arising from the use of information contained in these "Just Accepted" manuscripts. 


\title{
Mercury Sulfide Dimorphism in Thioarsenate
}

\section{Glasses}

\author{
M. Kassem,${ }^{\dagger}$ A. Sokolov ${ }^{\dagger}$ A. Cuisset ${ }^{\dagger}$ T. Usuki, ${ }^{\dagger}$ S. Khaoulani, ${ }^{\dagger}$ P. Masselin, ${ }^{\dagger}$ D. Le Coq,${ }^{\|}$ \\ J. C. Neuefeind, ${ }^{\S}$ M. Feygenson, ${ }^{\S}$ A. C. Hannon, ${ }^{\#}$ C. J. Benmore, ${ }^{\curvearrowright}$ and E. Bychkov ${ }^{* \dagger}$ \\ ${ }^{\dagger}$ Université du Littoral Côte d'Opale, LPCA, EA CNRS 4493, F-59140 Dunkerque, France \\ $\$$ Faculty of Science, Yamagata University, Yamagata 990-8560, Japan \\ " Sciences Chimiques de Rennes, UMR CNRS 6226, Eq. Verres et Céramiques, Université de \\ Rennes I, F-35042 Rennes, France \\ $\S$ Neutron Scattering Science Directorate, Oak Ridge National Laboratory, 1 Bethel Valley Road, \\ Oak Ridge, TN 37831-6475, USA \\ \# ISIS Facility, Rutherford Appleton Laboratory, Chilton, Didcot, OX11 0QX, UK \\ ${ }^{\diamond}$ X-ray Science Division, Argonne National Laboratory, Argonne, IL 60439, USA
}




\begin{abstract}
Crystalline mercury sulfide exists in two drastically different polymorphic forms in different domains of the $P, T$-diagram: red chain-like insulator $\alpha$-HgS, stable below $344{ }^{\circ} \mathrm{C}$, and black tetrahedral narrow-band semiconductor $\beta-\mathrm{HgS}$, stable at higher temperatures. Using pulsed neutron and high-energy X-ray diffraction, we show that these two mercury bonding pattern are present simultaneously in mercury thioarsenate glasses $\mathrm{HgS}-\mathrm{As}_{2} \mathrm{~S}_{3}$. The population and interconnectivity of chain-like and tetrahedral dimorphous forms determine both the structural features and fundamental glass properties (thermal, electronic, etc.). DFT simulations of mercury species and RMC modelling of high-resolution diffraction data provide additional details on local $\mathrm{Hg}$ environment and connectivity implying the $\left(\mathrm{HgS}_{2 / 2}\right)_{m}$ oligomeric chains $(1 \leq m \leq 6)$ are acting as a network former while the $\mathrm{HgS}_{4 / 4}$-related mixed agglomerated units behave as a modifier.
\end{abstract}




\section{INTRODUCTION}

The vast majority of crystals exists in several polymorphic forms in different domains of the $P, T$ diagram. Liquids and glasses also exhibit density- and entropy-driving polyamorphism, ${ }^{1-5}$ and the question remains whether the liquid-liquid or amorphous-amorphous transformation appears to be a phase transition of the first or second order. ${ }^{6-8}$ Molecular chalcogenide glasses synthesized in high pressure/high temperature conditions often show two polyamorphic forms simultaneously, i.e., a molecular cage and a network-related motif. ${ }^{9,10}$ The network-related population increases with applied pressure squashing the cage molecules. Here we report a different phenomenon: mercury sulfide dimorphism in network glasses synthesized in usual conditions without external stimuli. The term 'dimorphism' in this particular glass system is used to emphasize the origin of $\mathrm{HgS}_{2 / 2}$ and $\mathrm{HgS}_{4 / 4}$ units deriving from the two drastically different polymorphic forms of mercury sulfide, low-temperature cinnabar $\alpha$-HgS and hightemperature metacinnabar $\beta$-HgS.

Chalcogenide glasses transparent in the far IR region $(\lambda>15 \mathrm{~mm})$ are critically important for many optical systems. Selective remote IR spectroscopy of various biotoxin and gas species, thermal imaging, interstellar IR detection of life signature at exoplanetary systems, etc. ${ }^{11-14}$ represent only a few examples. Mercury chalcogenide glasses are particularly promising for these applications. Surprisingly, very little is known about their structure and properties. Using Raman spectroscopy and DFT modelling, we have shown recently that mercury thioarsenate glasses $\mathrm{HgS}-\mathrm{As}_{2} \mathrm{~S}_{3}$ form a hybrid $\mathrm{Hg}-\mathrm{S}$ chain/As-S pyramidal network. ${ }^{15}$ Nevertheless, the presence of a small fraction of $\mathrm{HgS}_{4 / 4}$ tetrahedral units in the hybrid network cannot be excluded completely since the Raman spectra of crystalline references, trigonal cinnabar $\alpha-\mathrm{HgS}(\mathrm{Hg}-\mathrm{S}$ 
chains) and cubic metacinnabar $\beta-\mathrm{HgS}\left(\mathrm{HgS}_{4 / 4}\right.$ tetrahedra), were found to be rather similar in the stretching region. ${ }^{16-18}$ Consequently, the two possible structural motifs in glasses may have similar Hg-S stretching frequencies. Pulsed neutron and high-energy X-ray diffraction over a wide $Q$-range combined with DFT simulation of 4-fold coordinated mercury entities and RMC modelling of the diffraction data are necessary to solve this structural puzzle. High-resolution diffraction results and comprehensive analysis allow a reliable conclusion to be drawn concerning dual structural role of mercury acting as either a network-former or a modifier. We will show that this structural analysis appears to be consistent with basic thermal and electronic glass properties. In addition, it should also be noted the lack of diffraction studies for mercury chalcogenide glasses probably related to high mercury absorption for both $\mathrm{X}$-rays $\left(Z_{\mathrm{Hg}}=80\right)$ and neutrons $\left(\sigma_{\mathrm{abs}}=372.3\right.$ barns $\left.^{19}\right)$. The paper will unveil the structural features of these exciting glasses in the $Q$ - and $r$-space. This understanding will be beneficial for their practical applications in optical systems and chemical sensing.

\section{EXPERIMENTAL SECTION}

Glass preparation. The quasi-binary $(\mathrm{HgS})_{x}\left(\mathrm{As}_{2} \mathrm{~S}_{3}\right)_{1-x}$ samples $(x=0.0,0.05,0.1,0.2$, $0.3,0.4,0.5)$ were prepared from $\mathrm{HgS}$ and $\mathrm{As}_{2} \mathrm{~S}_{3}$. Red mercury sulfide $\alpha-\mathrm{HgS}$ (99.99\% pure, Sigma-Aldrich) was used for synthesis of $\mathrm{HgS}-\mathrm{As}_{2} \mathrm{~S}_{3}$ samples without additional purification. Arsenic sulfide $\mathrm{As}_{2} \mathrm{~S}_{3}$ was prepared from arsenic pieces (99.9999\% pure, Cerac) and sulfur pellets (99.999\% pure, Acros Organics). Arsenic and sulfur were purified from $\mathrm{As}_{2} \mathrm{O}_{3}$ and $\mathrm{SO}_{2}$ oxides at the surface by heating under vacuum at $320{ }^{\circ} \mathrm{C}$ and $130{ }^{\circ} \mathrm{C}$, respectively. The detailed synthesis and homogenization procedure was described elsewhere. ${ }^{15}$ The obtained glasses were 


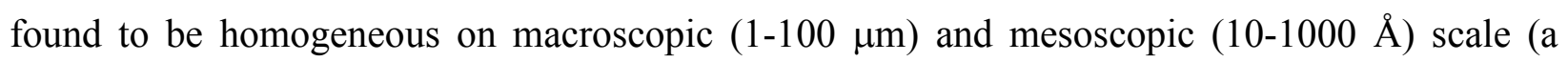
single glass transition over the entire glass forming range, $0.0 \leq x \leq 0.5,{ }^{15}$ and the absence of small-angle neutron and X-ray scattering in contrast to a typical behavior of phase-separated glasses; Fig. S1, Supporting information).

Diffraction measurements. Neutron diffraction experiments were carried out using the ISIS spallation neutron source (Rutherford-Appleton Laboratory, UK) and the SNS facility (OakRidge National Laboratory, USA). The SANDALS $(x=0,0.1,0.2$, and 0.4 samples), GEM $(x=$ $0.05)$ and NOMAD $(x=0.05,0.3,0.5)$ diffractometers ${ }^{20-23}$ at ISIS and SNS provide diffraction data over an extended range in reciprocal space (values of scattering vector $Q=4 \pi \sin \theta / \lambda$ up to $50 \AA^{-1}$; where $2 \theta$ is the scattering angle, $\lambda$ the neutron wavelength), leading to high resolution in real space. The neutron diffraction data were corrected $^{22,24}$ for background and container scattering, self-attenuation, multiple scattering, and inelasticity (Placzek) effects to obtain the total neutron structure factor $S_{N}(Q)$.

High-energy X-ray diffraction experiments were conducted at the 6-ID-D beam $\operatorname{line}^{25}$ at APS (Argonne National Laboratory, USA). The X-ray energy was $100 \mathrm{keV}$, providing data at $Q$ values up to $30 \AA^{-1}$. A 2D setup was used for data collection with a Perkin Elmer model $1621 \mathrm{X}$ ray area detector. The two dimensional diffraction patterns were reduced using the Fit $2 \mathrm{D}^{26}$ software. The measured background intensity was subtracted and corrections were made for the different detector geometries and efficiencies, sample self-attenuation and Compton scattering using standard procedures ${ }^{27,28}$ giving the total X-ray structure factor $S_{X}(Q)$.

DFT simulation. The DFT calculations have been carried out using GAUSSIAN 09 software $^{29}$ associated with its graphical user interface GaussView. In order to find a compromise 
between the cost of the calculations and the accuracy of the results, structural optimization and harmonic vibrational frequency calculations were performed for size-limited clusters composed of isolated $\mathrm{HgS}_{4}\left(\mathrm{H}_{4}\right)$ and $\mathrm{HgS}_{3}\left(\mathrm{H}_{3}\right)$ units, mixed $\mathrm{Hg}_{2} \mathrm{~S}_{5}\left(\mathrm{H}_{4}\right), \mathrm{Hg}_{3} \mathrm{~S}_{6}\left(\mathrm{H}_{4}\right), \mathrm{Hg}_{3} \mathrm{~S}_{8}\left(\mathrm{H}_{6}\right)$ and hybrid $\mathrm{HgAsS}_{6}\left(\mathrm{H}_{5}\right)$ clusters. Our previous DFT modelling of the chalcogenide glass vibrational properties $^{15,30}$ has shown that the above cluster size is sufficient to adequately represent the characteristic vibration modes in the glass and follow compositional trends. The terminal hydrogen atoms will be omitted in further discussions.

The DFT calculations were carried out with the Becke $^{31}$ three parameters hybrid exchange functional and the Lee-Yang-Parr correlation functional (B3LYP). ${ }^{32}$ The rather large 6-311G++(3df,2p) basis-set was used for arsenic, sulfur and hydrogen. In the case of atoms with a heavy nucleus like mercury, relativistic effects due to the inner core electrons having a velocity close to the speed of light should be taken into account. For Hg atoms, we have declared in the input file an external pseudo-potential or Effective Core Potential available in the Environment Molecular Science Library. ${ }^{33}$ The small-core relativistic pseudo-potential basis set (cc-pVTZPP) ${ }^{34}$ was specifically employed. All the structures were optimized using the tight convergence option ensuring adequate convergence and reliability of computed wavenumbers.

Reverse Monte Carlo modelling. The diffraction data of the $x=0.4$ glass were used for Reverse Monte Carlo (RMC) modelling. Initial random configurations of 760 and 7600 atoms were created and refined using the RMC_POT ++ package $^{35,36}$ which is a $\mathrm{C}++$ implementation of the RMC algorithm ${ }^{37-40}$ for deriving structures of disordered materials from experimental data. The small configuration was used to adjust constraints; the larger model (800 Hg, $2400 \mathrm{As}$ and $4400 \mathrm{~S}$ atoms positioned inside a cubic box with a side length of $58.26 \AA$ matching the experimental number density) was applied for final simulation. Atomic configurations were 
generated first by running a conventional hard sphere Monte Carlo simulation. The following $a$ priori information was used to constrain the configurations: (i) the hard-sphere closest approaches between different types of atoms (cut-off distances), and (ii) the coordination number constraints. The cut-off distances are given in Table 1. The measured neutron and X-ray structure factors, $S_{N}(Q)$ and $S_{X}(Q)$, and neutron pair distribution function $g_{N}(r)$ were then used to generate RMC models. The simulated structural functions, calculated from a configuration of atomic positions with periodic boundary conditions, were refined in comparison with experimental data. A typical number of generated/accepted moves for the larger simulation box was about $2.0 \times 10^{7} / 1.6 \times 10^{6}$ in order to minimize the differences between a simulated and experimental function. RMC simulations were performed using a multiprocessor calculation server; the algorithm converges to a local minimum during a few hours or a few days depending on number of atoms in the configuration.

Table 1. Hard-sphere closest approaches (cut-off distances) for different atom pairs used in RMC modelling of $0.4 \mathrm{HgS}-0.6 \mathrm{As}_{2} \mathrm{~S}_{3}$ glass

\begin{tabular}{ccccccc}
\hline Atom pair & As-S & $\mathrm{Hg}-\mathrm{S}$ & $\mathrm{As}-\mathrm{As}$ & $\mathrm{As}-\mathrm{Hg}$ & $\mathrm{Hg}-\mathrm{Hg}$ & $\mathrm{S}-\mathrm{S}$ \\
\hline $\begin{array}{c}\text { Cut-off } \\
\text { distance }(\AA)\end{array}$ & 2.0 & 2.15 & 2.8 & 3.3 & 3.3 & 2.8 \\
\hline
\end{tabular}

\section{RESULTS AND DISCUSSION}

Diffraction: $Q$-space. Weighted average structure factors $S(Q)$ were derived from the measured scattering cross section per atom $\mathrm{d} \sigma / \mathrm{d} \Omega$ through the relation

$$
\frac{\mathrm{d} \sigma}{\mathrm{d} \Omega}=\left|\sum_{a} c_{a} \bar{b}_{a}\right|^{2}(S(Q)-1)+\sum_{a} c_{a} \bar{b}_{a}^{2}
$$


in the case of neutron scattering, where $c_{a}, \bar{b}_{a}$ and $\bar{b}_{a}^{2}$ are, respectively, the atomic concentration, the average (over isotopes and spin states) of the neutron-nucleus scattering length, and the mean square scattering length of element $a$. In the X-ray case, $\bar{b}_{a}$ in eq. (1) is replaced by $f_{a}(Q)$, the atomic scattering factor of element $a$, which is $Q$ dependent.
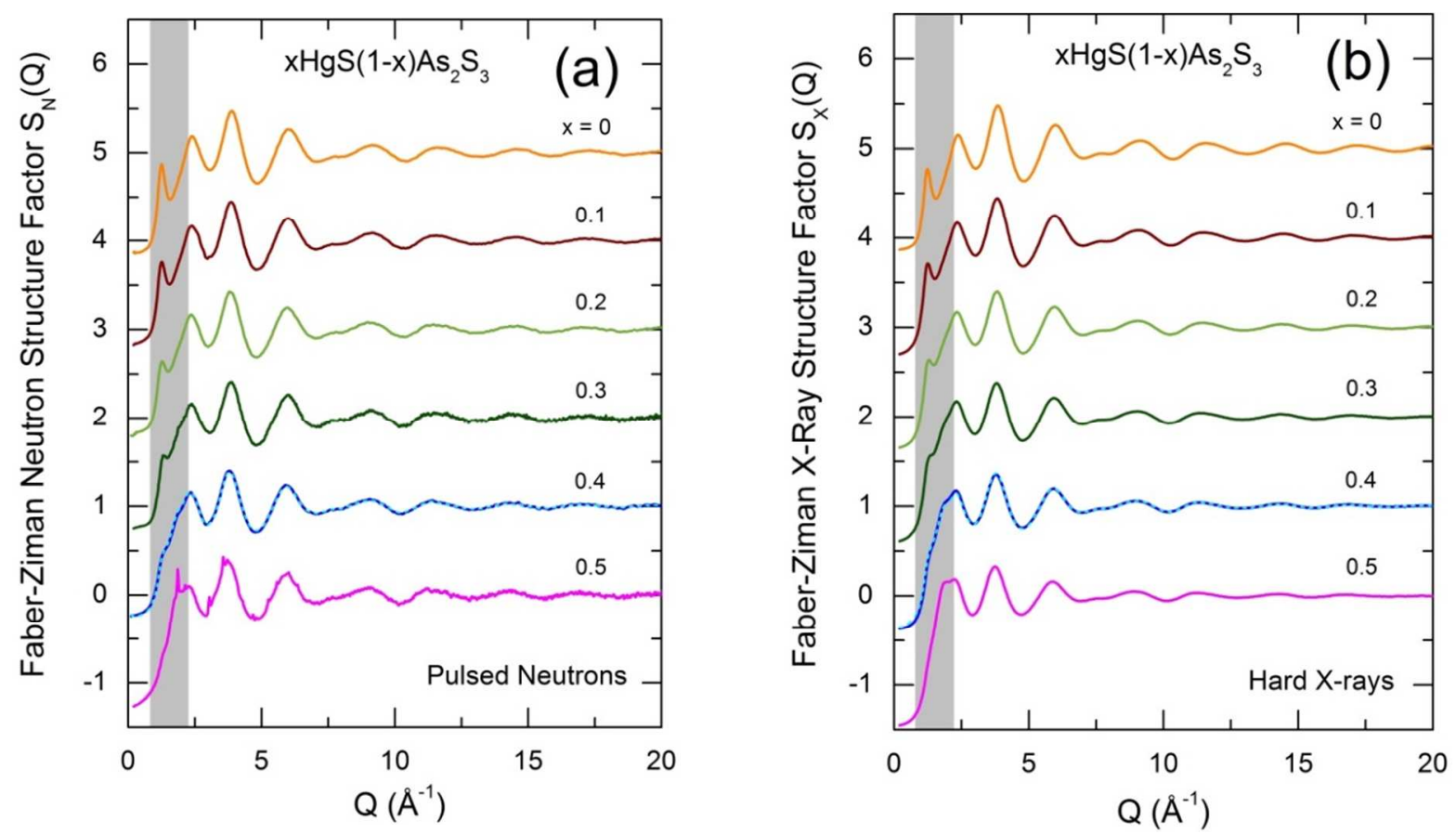

Figure 1. Typical (a) neutron $S_{N}(Q)$ and (b) X-ray $S_{X}(Q)$ structure factors of mercury thioarsenate glasses $(\mathrm{HgS})_{x}\left(\mathrm{As}_{2} \mathrm{~S}_{3}\right)_{1-x}, 0 \leq x \leq 0.5$, shown over a limited $Q$-range. Remarkable changes in the low- $Q$ region below $2 \AA^{-1}$ are highlighted in grey. RMC simulated $S_{N}(Q)$ and $S_{X}(Q)$ for the $x=0.4$ glass are shown by the dashed lines.

Typical neutron and X-ray structure factors of mercury thioarsenate glasses $(\mathrm{HgS})_{x}\left(\mathrm{As}_{2} \mathrm{~S}_{3}\right)_{1-x}$ are shown in Fig. 1. We note distinct high- $Q$ oscillations, observed up to $40 \AA^{-1}$ for glassy $\mathrm{As}_{2} \mathrm{~S}_{3}$, which are decreasing in amplitude with increasing $\mathrm{HgS}$ content $x$. Small Bragg peaks, related to cubic metacinnabar $\beta$-HgS, were observed only for large $x=0.5$ neutron sample $(\approx 3 \mathrm{~g})$ and absent for all other glasses including tiny $x=0.5 \mathrm{X}$-ray specimen, synthesized and quenched in thin-walled silica tube in small quantity $(0.1 \mathrm{~g})$. The most prominent changes were 
observed in the low- $Q$ region, $Q<2 \AA^{-1}$, highlighted in grey in Fig. 1. The published data ${ }^{41-45}$ for vitreous $g-\mathrm{As}_{2} \mathrm{~S}_{3}$ are similar to our results.

Glassy arsenic sulfide is characterized by a well-defined intermediate-range order (IRO) manifested by the first sharp diffraction peak (FSDP) at $Q_{0}=1.24 \AA^{-1} \cdot{ }^{41-47}$ As-As correlations with a characteristic length scale $L_{0} \cong 2 \pi / Q_{0}=5.1 \AA$ are responsible for the $\mathrm{FSDP}^{43,48-50}$ and represent average repeating As-As distances within or between $\mathrm{As}_{n} \mathrm{~S}_{n}$ rings, the origin of intermediate-range ordering in $g-\mathrm{As}_{2} \mathrm{~S}_{3}$. Layered monoclinic orpiment $c-\mathrm{As}_{2} \mathrm{~S}_{3}$ consists of $\mathrm{As}_{6} \mathrm{~S}_{6}$ rings and each arsenic atom participates in three neighboring rings. ${ }^{51}$ The As-As intra-ring and short interlayer correlations in $c-\mathrm{As}_{2} \mathrm{~S}_{3}$ cover the $5.05 \leq r(\mathrm{As}-\mathrm{As}) \leq 5.85 \AA$ range. The ring size $n$ appears to be variable in glassy arsenic sulfide. ${ }^{52}$

A new low- $Q$ feature appears and grows with increasing mercury sulfide content in $(\mathrm{HgS})_{x}\left(\mathrm{As}_{2} \mathrm{~S}_{3}\right)_{1-x}$ glasses. In order to extract the parameters of the two pre-peaks, a Voigt function was used to approximate the background underneath the features, ${ }^{24}$ allowing the pre-peaks to be isolated and fitted with Gaussians. Figure 2 shows the two pre-peaks as a function of $x$.
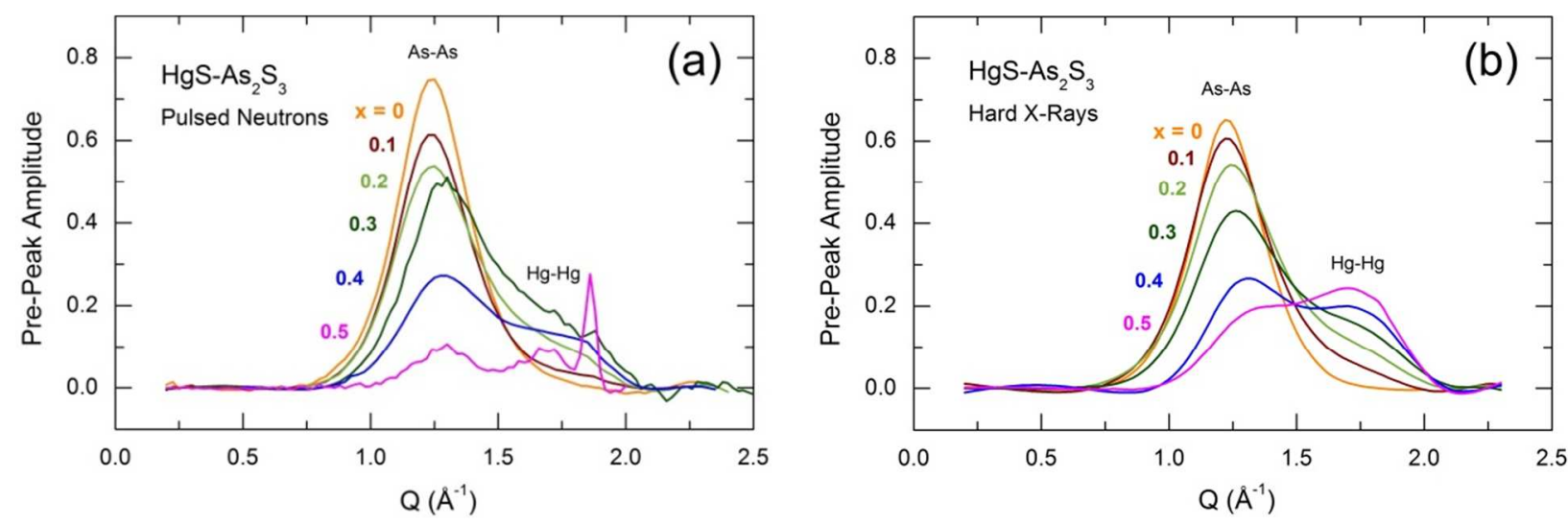

Figure 2. Two pre-peaks at $Q_{0 \mathrm{~A}} \approx 1.3 \AA^{-1}$ (As-As correlations) and $Q_{0 \mathrm{~B}} \approx 1.7 \AA^{-1}$ (Hg-Hg correlations) isolated from (a) neutron $S_{N}(Q)$ and (b) X-ray $S_{X}(Q)$ structure factors for $(\mathrm{HgS})_{x}\left(\mathrm{As}_{2} \mathrm{~S}_{3}\right)_{1-x}$ glasses. 
The first pre-peak at $Q_{0 \mathrm{~A}} \approx 1.3 \AA^{-1}$, corresponding to As-As IRO correlations in the $\mathrm{As}_{2} \mathrm{~S}_{3}$ host matrix, decreases with increasing $x$. Its amplitude $A_{0 \mathrm{~A}}$ in neutron data is slightly higher than that for hard X-rays, consistent with neutron and X-ray As-As weighting factors in the mercury thioarsenate glasses, $1.10 \leq \frac{W_{\mathrm{As}-\mathrm{As}}^{N}}{W_{\mathrm{As}-\mathrm{As}}^{X}} \leq 1.26$, where $w_{a b}^{N}=\left(2-\delta_{a b}\right) \frac{c_{a} \bar{b}_{a} c_{b} \bar{b}_{b}}{\left|\sum_{a} c_{a} \bar{b}_{a}\right|^{2}}$ is the neutron weighting factor for the atom pair $(a, b)$ and $\delta_{a b}$ is the Kronecker delta function. In the X-ray case, $\bar{b}_{a}$ is replaced by $Q$-dependent atomic scattering factor $f_{a}(Q)$, see also eq. (1) for further details. In contrast, the second pre-peak at $Q_{0 \mathrm{~B}} \approx 1.7 \AA^{-1}$ grows with mercury sulfide content, and the $A_{0 \mathrm{~B}}$ amplitude is slightly higher for the $S_{X}(Q)$ structure factors, correlating with $\mathrm{Hg}-\mathrm{Hg}$ weighting factors, $0.70 \leq \frac{W_{\mathrm{Hg}-\mathrm{Hg}}^{N}}{W_{\mathrm{Hg}-\mathrm{Hg}}^{X}} \leq 0.80$. Spatial periodicity related to the second pre-peak, i.e., a characteristic length scale $L_{0 \mathrm{~B}}$ deduced from $Q_{0 \mathrm{~B}}, L_{0 \mathrm{~B}} \cong 2 \pi / Q_{0 \mathrm{~B}}=3.7 \AA$, is similar to $\mathrm{Hg}-\mathrm{Hg}$ intrachain second neighbor distance in $\alpha-\operatorname{HgS}(3.75 \AA)^{53}$ and distinctly shorter than the closest $\mathrm{Hg}-\mathrm{Hg}$ interchain correlations $(4.10-4.15 \AA)^{53}$ or $\mathrm{Hg}-\mathrm{Hg}$ second neighbor contacts in $\beta$-HgS $(4.14 \AA) .{ }^{54}$ Consequently, the appearance and position of the second pre-peak seems to be related to $\mathrm{Hg}-\mathrm{Hg}$ correlations in $\left(\mathrm{HgS}_{2 / 2}\right)_{m}$ zig-zag chains existing in hybrid chain/pyramidal network of $\mathrm{HgS}-\mathrm{As}_{2} \mathrm{~S}_{3}$ glasses.

The origin of the two pre-peaks is clearly seen on difference structure factors $\Delta S(Q)$ without As-As or $\mathrm{Hg}-\mathrm{Hg}$ correlations (Fig. 3) calculated using a combination of neutron and high-energy X-ray diffraction data and removing $\mathrm{Hg}-\mathrm{Hg}$ correlations as an example:

$$
\Delta S_{-\mathrm{HgHg}}(Q)-1=\left\{\left[S_{X}(Q)-1\right]-\frac{W_{\mathrm{HgHg}}^{X}(Q)}{W_{\mathrm{HgHg}}^{N}}\left[S_{N}(Q)-1\right]\right\} \frac{W_{\mathrm{AsAs}}^{X}(Q)}{W_{\mathrm{AsAs}}^{X}(Q)-\frac{W_{\mathrm{HgHg}}^{X}(Q)}{W_{\mathrm{HgHg}}^{N}} W_{\mathrm{AsAs}}^{N}},
$$


where $S_{X}(Q)$ and $S_{N}(Q)$ are the Faber-Ziman X-ray and neutron structure factors, $W_{a b}^{X}(Q)$ are the $Q$-dependent X-ray weighting factors, and $W_{a b}^{N}$ are the neutron weighting coefficients. The second term in eq. (2) normalizes the difference $\Delta S(Q)$ structure factor to the original (before subtraction) As-As correlations.

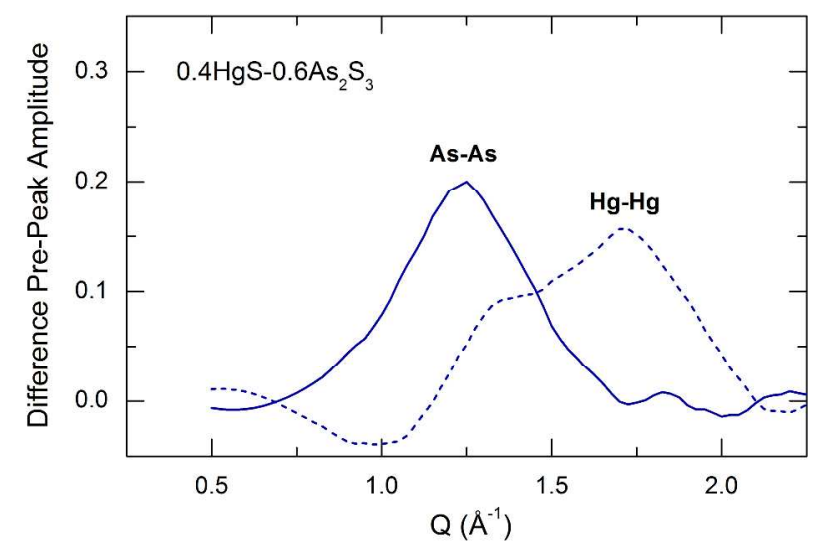

Figure 3. The $1.3 \AA^{-1}$ (As-As) and $1.7 \AA^{-1}(\mathrm{Hg}-\mathrm{Hg})$ pre-peaks isolated from the difference structure factors $\Delta S(Q)$ without As-As (the dashed line) or $\mathrm{Hg}-\mathrm{Hg}$ correlations (the solid line) for the $x=0.4$ glass.

The pre-peak at $1.7 \AA^{-1}$ is absent for $\Delta S(Q)$ without $\mathrm{Hg}-\mathrm{Hg}$ correlations, while the subtraction procedure for the $1.3 \AA^{-1}$ pre-peak leaves some residuals on $\Delta S(Q)$ without As-As correlations, Fig. 3. Nevertheless, the negative or positive amplitude of these residuals is small compared to that of the $1.3 \AA^{-1}$ pre-peak. We have also verified a possible implication of As-Hg correlations in the $1.7 \AA^{-1}$ pre-peak. Subtracting the As-Hg term yields strong negative amplitude at $\approx 1.7 \AA^{-1}$ and also affects the As-As pre-peak at $\approx 1.3 \AA^{-1}$, Fig. S2 (Supporting information), since the As-Hg weighting is larger than the $\mathrm{Hg}-\mathrm{Hg}$ weighting for all compositions studied, for both X-rays and neutrons. Consequently, we are ruling out this possibility. 


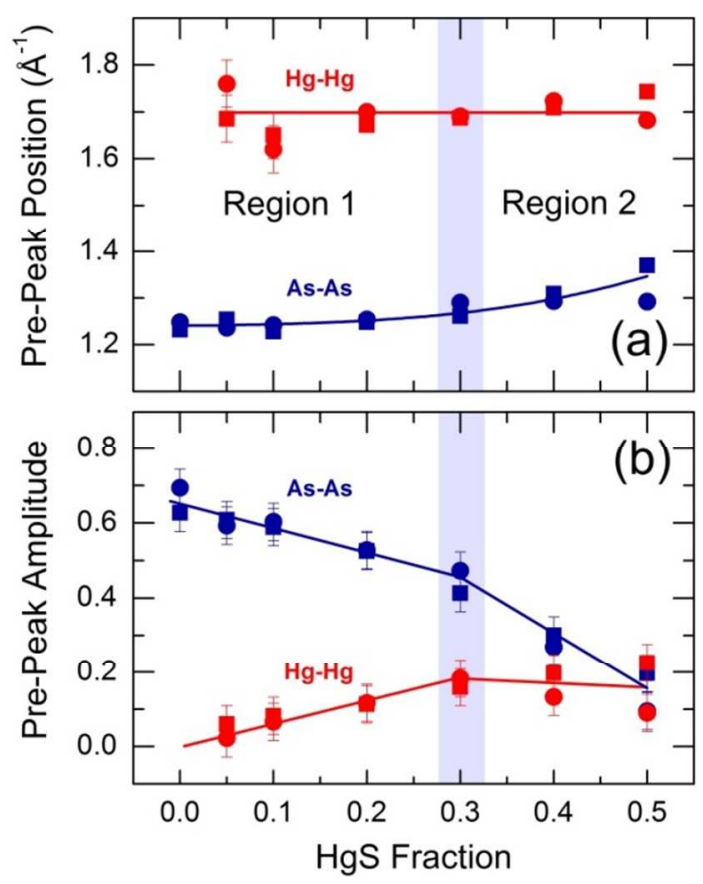

Figure 4. The $1.3 \AA^{-1}$ (As-As) and $1.7 \AA^{-1}$ (Hg-Hg) pre-peak (a) position and (b) amplitude in mercury thioarsenate glasses. Circles and squares correspond to neutron and X-ray data, respectively. The threshold concentration $x_{0} \approx 0.3$ between Regions 1 and 2 is highlighted in blue. The lines are drawn as a guide to the eye.

The composition dependences of the pre-peak amplitudes $\left(A_{0 \mathrm{~A}}, A_{0 \mathrm{~B}}\right)$ and positions $\left(Q_{0 \mathrm{~A}}, Q_{0 \mathrm{~B}}\right)$, shown in Fig. 4 , exhibit a critical behavior with the threshold concentration $x_{0} \approx 0.3$. A nearly linear decrease of the $A_{0 \mathrm{~A}}(x)$ amplitude below $x_{0}$ (Region 1) is simply related to a diminishing $\mathrm{As}_{2} \mathrm{~S}_{3}$ fraction, $1-x$, with the increasing mercury sulfide content $x ; A_{0 \mathrm{~A}}(x)$ tends to 0 as $\mathrm{x} \rightarrow 1$. The $A_{0 \mathrm{~B}}(x)$ amplitude increases monotonically with $x$ up to $x_{0} \approx 0.3$. The both trends change for HgS-rich glasses. The $1.3 \AA^{-1}$ pre-peak starts to disappear rapidly at $x \geq x_{0}$ (Region 2), and $A_{0 \mathrm{~A}}(x)$ is expected to be zero just above the glass-forming limit. Simultaneously, one observes a distinct increase of $Q_{0 \mathrm{~A}}(x)$, which is constant below $x_{0}$. On the 
other hand, the $1.7 \AA^{-1}$ pre-peak stops growing above $x_{0}$ indicating a limiting role of $\left(\mathrm{HgS}_{2 / 2}\right)_{m}$ helical chains in further network transformation.

Diffraction: $r$-space. Total correlation functions $T_{N}(r)$ and $T_{X}(r)$ were derived through the usual Fourier transform,

$T(r)=4 \pi \rho_{0} r+\frac{2}{\pi} \int_{0}^{Q_{\max }} Q[S(Q)-1] \sin Q r M(Q) d Q$

where $\rho_{0}$ is the total number density, and $M(Q)$ is the Lorch modification function. ${ }^{55}$ Results for the $\mathrm{HgS}-\mathrm{As}_{2} \mathrm{~S}_{3}$ glasses are shown in Fig. 5 taking $Q_{\max }=30 \AA^{-1}$ for both neutron and X-ray data for comparative purposes. The atomic number densities were derived from the experimental glass density values. ${ }^{15}$

The total correlation function defined in eq. (3) is a weighted average of partial total correlation functions for the different atom pairs $(a, b)$ :

$T(r)=\sum_{a b} W_{a b} T_{a b}(r)=\sum_{a b} c_{a} c_{b} \frac{\bar{b}_{a} \bar{b}_{b}}{\left|\sum_{a} c_{a} \bar{b}_{a}\right|^{2}} T_{a b}(r)$

A weighted average coordination number for a peak in $T(r)$ extending from $r_{x}$ to $r_{y}$ is defined as

$C=\int_{r_{x}}^{r_{y}} r T(r) d r$

Analogously to eq. (4), this $C$ is related to the partial coordination numbers $N_{a b}$ expressing the average number of $b$-atoms within the $r_{y}-r_{x}$ range from an $a$-atom at the origin ${ }^{56}$

$C=\sum_{a b} w_{a b} N_{a b}=\sum_{a b} c_{a} \frac{\bar{b}_{a} \bar{b}_{b}}{\left|\sum_{a} c_{a} \bar{b}_{a}\right|^{2}} N_{a b}$ 

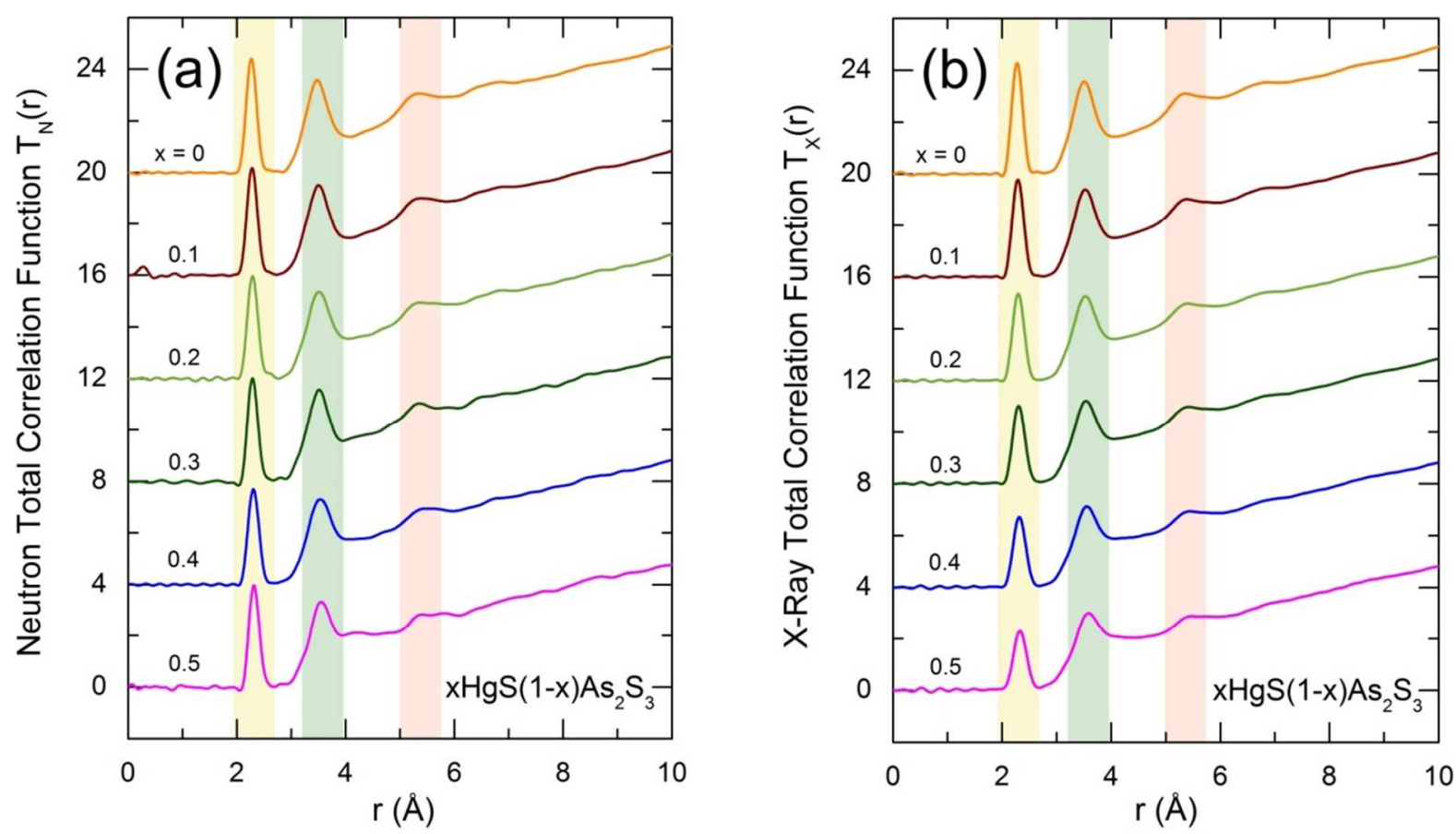

Figure 5. (a) Neutron $T_{N}(r)$ and (b) X-ray $T_{X}(r)$ total correlation functions of $(\mathrm{HgS})_{x}\left(\mathrm{As}_{2} \mathrm{~S}_{3}\right)_{1-x}$ glasses. The first neighbor peak at $\approx 2.3 \AA$, the second neighbor peak at $\approx 3.5 \AA$, and the $\mathrm{As}_{n} \mathrm{~S}_{n}$ center-center correlations at $\approx 5.2 \AA$ are highlighted in yellow, green and orange respectively.

Glassy $\mathrm{As}_{2} \mathrm{~S}_{3}$ shows three characteristic peaks in real-space functions: (i) a narrow peak at $2.27 \AA$ corresponding to As-S first neighbor correlations; (ii) a broad peak at $\approx 3.5 \AA$ related to As-As, S-S and As-S second neighbor intra-layer contacts and shortest interlayer correlations; (iii) a distinct feature at $\approx 5.2 \AA$ reflecting center-center correlations between $\operatorname{As}_{n} \mathrm{~S}_{n} \operatorname{rings}\left(\mathrm{As}_{6} \mathrm{~S}_{6}\right.$ in monoclinic $c-\mathrm{As}_{2} \mathrm{~S}_{3}$ ). The area of the $2.27 \AA$ peak confirms trigonal arsenic coordination, $N_{\text {As-S }} \approx 3$.

The $2.27 \AA$ peak decreases in $(\mathrm{HgS})_{x}\left(\mathrm{As}_{2} \mathrm{~S}_{3}\right)_{1-x}$ glasses following the $(1-x)$ concentration factor. In addition, a distinct asymmetric high- $r$ broadening is observed with increasing $x$. This broadening is expected since the $\mathrm{Hg}-\mathrm{S}$ first neighbour distance in trigonal cinnabar $\alpha-\mathrm{HgS}$ is $2.38 \AA$ and that in cubic metacinnabar $\beta-\mathrm{HgS}$ is $2.54 \AA .^{53,54} \mathrm{~A}$ new broad feature at $\approx 4 \AA$ appears 
and increases with $x$. This change is also expected since the second neighbour correlations at $4 \AA$ $\leq r \leq 5 \AA$ exist in both $\alpha$ - and $\beta$-HgS. Finally, the $5.2 \AA$ feature broadens and becomes less intense with increasing $x$.

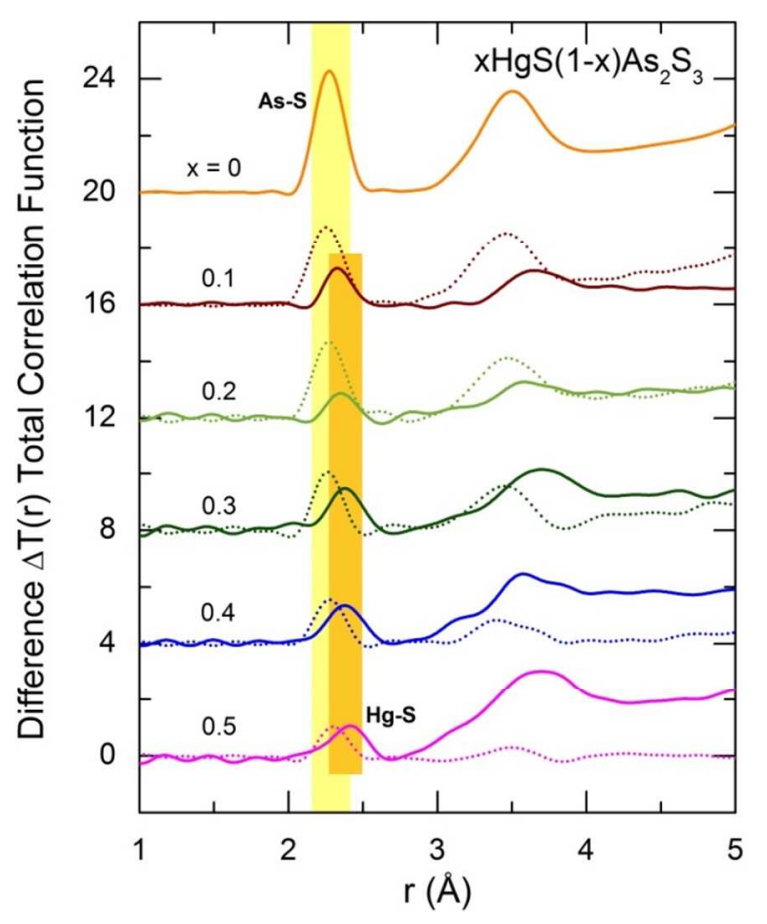

Figure 6. Difference total correlation functions $\Delta T(r)$ for $\mathrm{HgS}-\mathrm{As}_{2} \mathrm{~S}_{3}$ glasses obtained by combination of neutron and X-ray diffraction data for each glass composition. The solid lines correspond to $\Delta T(r)$ without As-S correlations. The dotted lines are $\Delta T(r)$ 's without Hg-S correlations. The As-S and Hg-S first neighbor correlations are highlighted in yellow and dark yellow, respectively.

Two contributions to the first neighbor peak at $\approx 2.3 \AA$ are clearly visible on difference correlation functions $\Delta T(r)$, Fig. 6, obtained using a combination of neutron and X-ray diffraction data for each glass composition, eq. (2). Different neutron and X-ray weighting factors for As-S, $W_{\mathrm{As}-\mathrm{S}}^{N}(x)$ and $W_{\mathrm{As}-\mathrm{S}}^{X}(x)$, and $\mathrm{Hg}-\mathrm{S}$ pairs, $W_{\mathrm{Hg}-\mathrm{S}}^{N}(x)$ and $W_{\mathrm{Hg}-\mathrm{S}}^{X}(x)$, allow $\Delta T(r)$ to be calculated without As-S (the solid lines in Fig. 6) or Hg-S correlations (the dotted 
lines in Fig. 6). As a result, the overlapping first neighbor peak at $\approx 2.3 \AA$ for $T_{N}(r)$ 's and $T_{X}(r)$ 's (Fig. 5) appears to be split into two features in $\Delta T(r)$ functions.
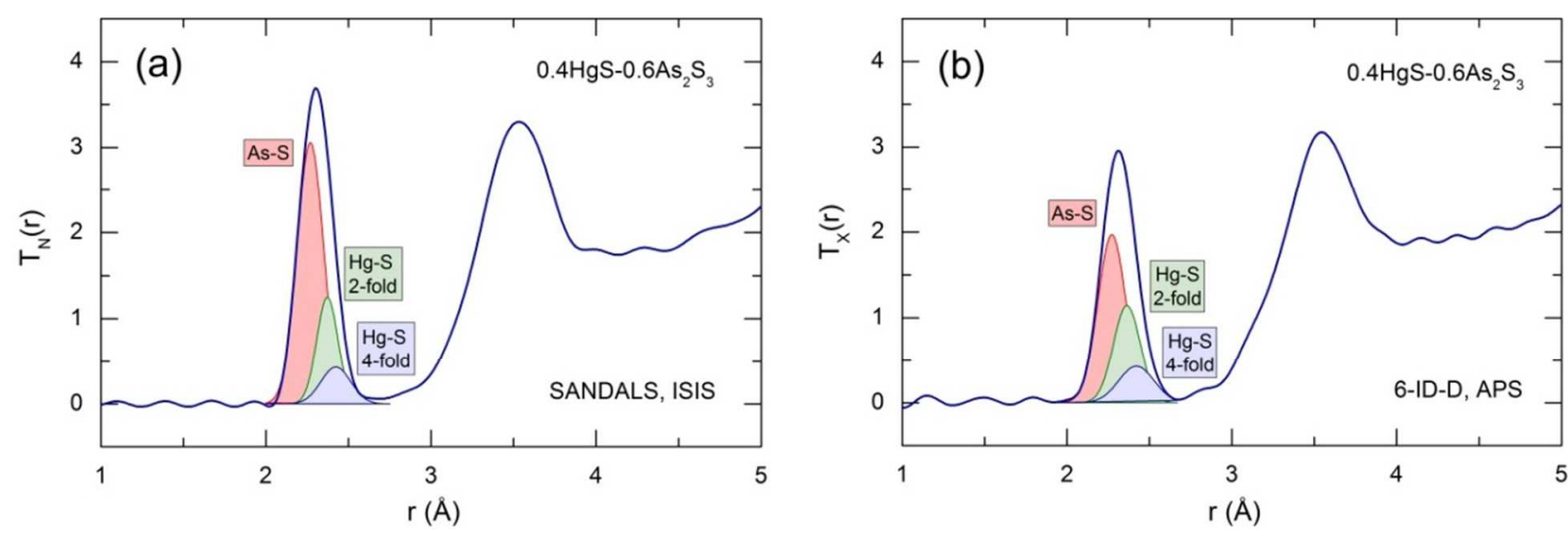

Figure 7. A three-peak fitting of the first feature in (a) neutron $T_{N}(r)$ and (b) X-ray $T_{X}(r)$ total correlation functions for the $x=0.4$ glass. The As- $\mathrm{S}$, two-fold $\mathrm{Hg}_{2 \mathrm{~F}}-\mathrm{S}$ and four-fold $\mathrm{Hg}_{4 \mathrm{~F}}-\mathrm{S}$ correlations are highlighted in red, green and blue, respectively.

Fitting the first peak in $T_{N}(r)$ and $T_{X}(r)$ with two Gaussians yields $N_{\mathrm{As}-\mathrm{S}} \approx 3$ and $N_{\mathrm{Hg}-\mathrm{S}} \geq 2$, the Hg-S coordination number is increasing with $x$. In other words, the four-fold coordinated mercury species appear in the glass network. In contrast, the trigonal arsenic coordination remains intact, consistent with Raman spectroscopy data. ${ }^{15}$ The fit quality deteriorates with $x$ since $r\left(\mathrm{Hg}_{4 F^{-}}-\mathrm{S}\right)>r\left(\mathrm{Hg}_{2 F^{-}} \mathrm{S}\right), 2.54$ vs. $2.38 \AA$ in crystalline $\beta$ - and $\alpha-\mathrm{HgS}$, respectively. Consequently, a three-peak fitting (Fig. 7) was necessary with the following constraint on $C_{\mathrm{Hg}}^{2 F}$ and $C_{\mathrm{Hg}}^{4 F}$ peak areas:

$2-\frac{C_{\mathrm{Hg}}^{2 F}}{w_{\mathrm{Hg}-\mathrm{S}}}=\frac{1}{2} \frac{C_{\mathrm{Hg}}^{4 F}}{w_{\mathrm{Hg}-\mathrm{S}}}$,

where $C_{\mathrm{Hg}}^{2 F}$ and $C_{\mathrm{Hg}}^{4 F}$ are the peak areas, defined by eq. (5), corresponding to 2-fold and 4-fold coordinated mercury, $w_{\mathrm{Hg}-\mathrm{S}}$ is the neutron or X-ray $\mathrm{Hg}-\mathrm{S}$ weighting factor. The obtained partial 
coordination numbers $N_{\mathrm{Hg}}^{2 F}$ and $N_{\mathrm{Hg}}^{4 F}$ were used to calculate the fraction of 4-fold coordinated $\mathrm{Hg}$ species $f_{\mathrm{Hg}}^{4 F}$ :

$$
f_{\mathrm{Hg}}^{4 F}=\frac{N_{\mathrm{Hg}-\mathrm{S}}^{4 F}}{4}=1-\frac{N_{\mathrm{Hg}-\mathrm{S}}^{2 F}}{2} .
$$
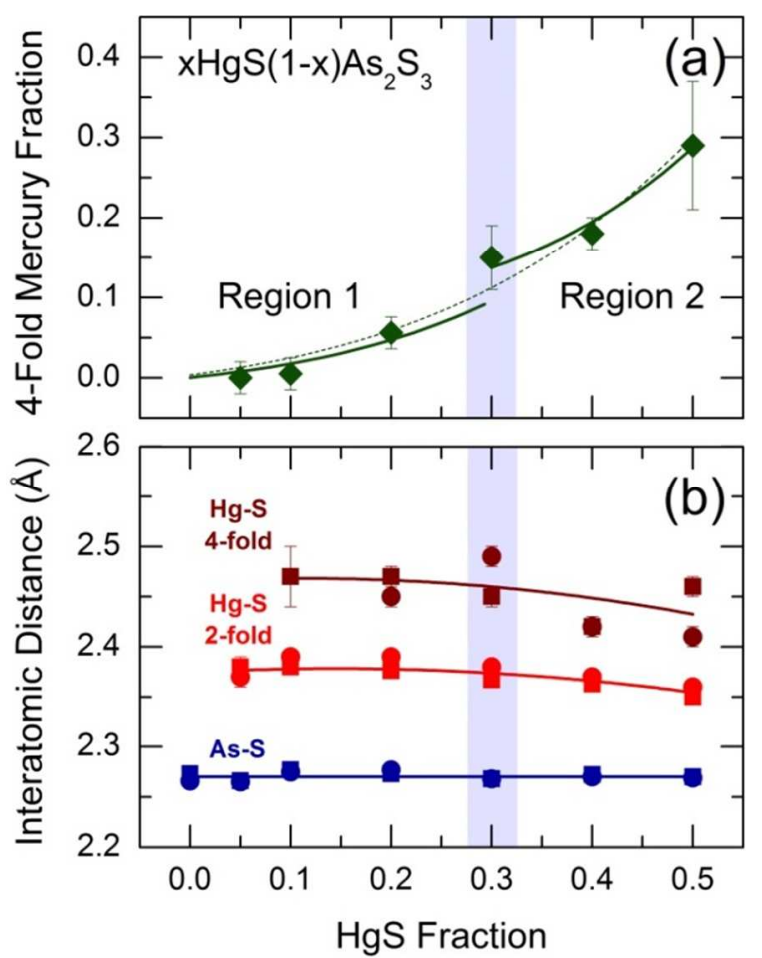

Figure 8. (a) The fraction of four-fold coordinated mercury $f_{\mathrm{Hg}}^{4 F}$ and (b) the first neighborAs- $\mathrm{S}, \mathrm{Hg}_{2 F^{-}}-\mathrm{S}$ and $\mathrm{Hg}_{4 F}-\mathrm{S}$ distances in $\mathrm{HgS}-\mathrm{As}_{2} \mathrm{~S}_{3}$ glasses plotted as a function of $x$. The average (neutron and X-ray) values are drawn for $f_{\mathrm{Hg}}^{4 F}$. The $x=0.5$ composition is characterized by large $\mathrm{n} / \mathrm{X}$ difference, probably because the neutron sample is partly crystallized. The first neighbor distances are shown separately for neutrons (circles) and X-rays (squares). The threshold concentration $x_{0} \approx 0.3$ is highlighted in blue. The lines are drawn as a guide to the eye.

The $f_{\mathrm{Hg}}^{4 F}$ fraction is negligible at $x \leq 0.1$ but increases with mercury sulfide content reaching $f_{\mathrm{Hg}}^{4 F} \approx 0.3$ for equimolar $\mathrm{HgS} / \mathrm{As}_{2} \mathrm{~S}_{3}$ composition $(x=0.5)$, Fig. 8 . The fitting results are given in Table 2 . 
Table 2. Structural parameters of $\mathrm{HgS}-\mathrm{As}_{2} \mathrm{~S}_{3}$ glasses obtained using pulsed neutron and highenergy X-ray diffraction: first neighbor interatomic distances, $r(\mathrm{As}-\mathrm{S}), \boldsymbol{r}\left(\mathrm{Hg}_{2 F^{-}} \mathrm{S}\right)$ and $\boldsymbol{r}\left(\mathrm{Hg}_{4 F^{-}} \mathrm{S}\right)$, for arsenic, two-fold and 4-fold coordinated mercury species; partial coordination numbers, $N_{\mathrm{As}-\mathrm{S}}, N_{\mathrm{Hg}-\mathrm{S}}^{2 F}$, and $N_{\mathrm{Hg}-\mathrm{S}}^{4 F}$.

\begin{tabular}{|c|c|c|c|c|c|c|}
\hline $\begin{array}{l}\text { HgS Fraction } \\
\qquad x\end{array}$ & $\begin{array}{c}r(\text { As- S }) \\
(\AA ̊)\end{array}$ & $N_{\mathrm{As}-\mathrm{S}}$ & $\begin{array}{c}r\left(\mathrm{Hg}_{2 F}-\mathrm{S}\right) \\
(\AA)\end{array}$ & $N_{\mathrm{Hg}-\mathrm{S}}^{2 F}$ & $\begin{array}{c}r\left(\mathrm{Hg}_{4 F}-\mathrm{S}\right) \\
(\AA)\end{array}$ & $N_{\mathrm{Hg}-\mathrm{S}}^{4 F}$ \\
\hline \multicolumn{7}{|c|}{ Neutron diffraction } \\
\hline 0.0 & $2.27(1)$ & $2.95(10)$ & - & - & - & - \\
\hline 0.05 & $2.27(1)$ & $2.96(10)$ & $2.37(3)$ & $1.95(10)$ & - & - \\
\hline 0.1 & $2.27(1)$ & $2.99(10)$ & $2.39(2)$ & $2.02(10)$ & - & - \\
\hline 0.2 & $2.28(1)$ & $2.97(10)$ & $2.39(2)$ & $1.90(10)$ & $2.45(3)$ & $0.23(10)$ \\
\hline 0.3 & $2.27(1)$ & $2.99(10)$ & $2.38(2)$ & $1.79(10)$ & $2.49(3)$ & $0.44(10)$ \\
\hline 0.4 & $2.27(1)$ & $3.01(10)$ & $2.37(2)$ & $1.61(10)$ & $2.42(2)$ & $0.80(10)$ \\
\hline $0.5^{*}$ & $2.27(1)$ & $3.00(1)$ & $2.36(2)$ & $1.25(10)$ & $2.41(2)$ & $1.50(10)$ \\
\hline \multicolumn{7}{|c|}{ High-energy x-ray diffraction } \\
\hline 0.0 & $2.27(1)$ & $2.94(10)$ & - & - & - & - \\
\hline 0.05 & $2.27(1)$ & $2.97(10)$ & $2.38(2)$ & $2.00(10)$ & - & - \\
\hline 0.1 & $2.28(1)$ & $3.00(10)$ & $2.38(1)$ & $1.95(10)$ & $2.47(2)$ & $0.10(10)$ \\
\hline 0.2 & $2.27(1)$ & $2.98(10)$ & $2.38(2)$ & $1.90(10)$ & $2.47(2)$ & $0.22(10)$ \\
\hline 0.3 & $2.27(1)$ & $3.00(10)$ & $2.37(1)$ & $1.65(10)$ & $2.45(2)$ & $0.73(10)$ \\
\hline 0.4 & $2.27(1)$ & $2.98(10)$ & $2.36(2)$ & $1.69(10)$ & $2.42(2)$ & $0.63(10)$ \\
\hline 0.5 & $2.27(1)$ & $2.94(10)$ & $2.35(2)$ & $1.59(10)$ & $2.46(2)$ & $0.80(10)$ \\
\hline
\end{tabular}

The derived fraction $f_{\mathrm{Hg}}^{4 F} \leq 0.3$ indicates that a majority of mercury species is two-fold coordinated and the hybrid chain/pyramidal network is the main structural motif in mercury thioarsenate glasses. A higher flexibility of the hybrid network compared to $g-\mathrm{As}_{2} \mathrm{~S}_{3}$ results in lower glass transition temperatures $T_{\mathrm{g}}(x)$, observed experimentally. ${ }^{15}$ 
The critical behavior is less evident for structural parameters in the $r$-space. We should note a certain discontinuity for $f_{\mathrm{Hg}}^{4 F}$ at $x_{0}$. The two Hg-S distances also start decreasing above $x_{0}$ (Region 2), $2.36 \AA \leq r\left(\mathrm{Hg}_{2 F}-\mathrm{S}\right) \leq 2.39 \AA$, and $2.41 \AA \leq r\left(\mathrm{Hg}_{4 F}-\mathrm{S}\right) \leq 2.49 \AA$. The latter distance appears to be distinctly shorter than $r\left(\mathrm{Hg}_{4 F}-\mathrm{S}\right)=2.54 \AA$ in cubic metacinnabar $\beta-\mathrm{HgS}$. However, the As-S first neighbor separation remains invariant over the entire composition range, $r($ As-S $) \approx 2.27 \AA$.

\section{Raman signature of 4-fold coordinated mercury species calculated using DFT. DFT} modelling of Raman spectra for four-fold coordinated mercury species has shown several interesting features: (1) a contrasting stability of isolated $\mathrm{HgS}_{4}$ molecules, (2) similar $\mathrm{Hg}-\mathrm{S}$ symmetric stretching frequencies for two-fold and 4-fold coordinated $\mathrm{Hg}$ entities with a distinct red shift for $\mathrm{HgS}_{4}$ units, and (3) a remarkable blue shift of $\approx 35 \mathrm{~cm}^{-1}$ between $\mathrm{A}_{1}$ symmetric stretching modes in crystalline $\mathrm{HgS}$ polymorphs and small $\mathrm{Hg}-\mathrm{S}$ clusters in contrast to a resemblance of DFT simulated and experimental frequencies in glasses.

First, an isolated $\mathrm{HgS}_{4}$ tetrahedral molecule ( $\mathrm{T}_{\mathrm{d}}$ symmetry) appears to be unstable and transforms into an $\mathrm{HgS}_{4}$ square ( $\mathrm{D}_{4 \mathrm{~h}}$ symmetry), Fig. 9(a). The calculated $\mathrm{Hg}-\mathrm{S}$ interatomic distances, $2.42 \AA$, are shorter than those in cubic metacinnabar $\beta-\mathrm{HgS}$ but similar to the $\mathrm{Hg}_{4 F^{-}} \mathrm{S}$ first neighbour contacts observed in diffraction experiments of $\mathrm{HgS}-\mathrm{As}_{2} \mathrm{~S}_{3}$ glasses, Fig. 8(b). A DFT Raman spectrum of the $\mathrm{HgS}_{4}$ square in the stretching region exhibits a bimodal feature: $\mathrm{Hg}$ $\mathrm{S}$ asymmetric and symmetric stretch at 269 and $287 \mathrm{~cm}^{-1}$, respectively, Fig. 9(b). Fixed tetrahedral geometry of $\mathrm{HgS}_{4}$ with identical $\angle \mathrm{S}-\mathrm{Hg}-\mathrm{S}$ angles of $109.47^{\circ}$ yields rather similar Raman spectrum. Nevertheless, negative (imaginary) frequencies for some bending and $\mathrm{H}$ related modes, are indicating again that isolated tetrahedral mercury species remain unstable. 

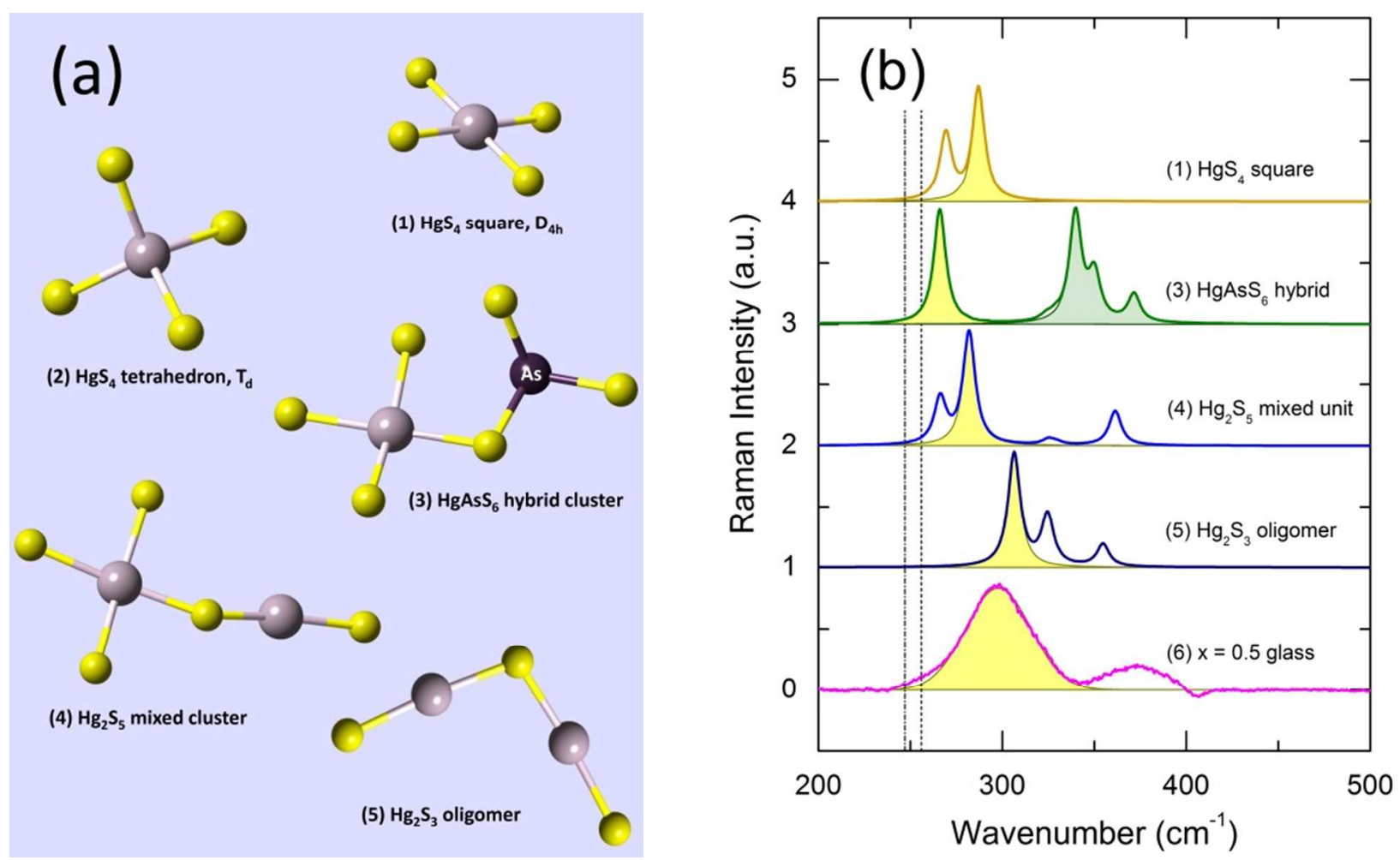

Figure 9. (a) Schematic representation of small Hg-S and Hg-As-S clusters used for DFT modelling; the terminal hydrogen species are omitted; (b) DFT Raman spectra in the stretching domain for (1) $\mathrm{HgS}_{4}$ square, (3) $\mathrm{HgAsS}_{6}$ hybrid cluster, (4) $\mathrm{Hg}_{2} \mathrm{~S}_{5}$ mixed unit, and (5) $\mathrm{Hg}_{2} \mathrm{~S}_{3}$ oligomer, ${ }^{15}$ plotted using fixed FWHM of $8 \mathrm{~cm}^{-1}$. The hydrogen-related modes are removed from the spectra. The spectrum for (2) isolated $\mathrm{HgS}_{4}$ tetrahedron is not shown because of imaginary frequencies. The highlighted features in yellow at $265-305 \mathrm{~cm}^{-1}$ correspond to symmetric $\mathrm{Hg}-\mathrm{S}$ stretching in mercury sulfide related fragments. The As-S stretching modes in hybrid $\mathrm{HgAsS}_{6}$ are highlighted in green. The dash-dotted and dashed lines at 247 and $256 \mathrm{~cm}^{-1}$ show the positions of the most intense vibrational modes in cubic metacinnabar $\beta$ $\mathrm{HgS}$ and trigonal cinnabar $\alpha-\mathrm{HgS}$, respectively. ${ }^{16-18}$ A typical difference Raman spectrum for (6) the $x=$ 0.5 glass is also shown. ${ }^{15}$

The tetrahedral instability persists in $\mathrm{Hg}_{2} \mathrm{~S}_{5}, \mathrm{Hg}_{3} \mathrm{~S}_{6}, \mathrm{Hg}_{3} \mathrm{~S}_{8}$ mixed units, and hybrid $\mathrm{HgAsS}_{6}$ clusters yielding the approximate $\mathrm{D}_{4 \mathrm{~h}}$ symmetry, Fig. 9(a), starting from regular $\mathrm{T}_{\mathrm{d}}$ configuration for an $\mathrm{HgS}_{4}$ molecule, Fig. S3 (Supporting information). The optimized geometry of $\mathrm{HgS}_{4}$ square is similar in all cases: the average $\mathrm{Hg}$-S distances remain $2.43 \pm 0.02 \AA$, while the $\angle \mathrm{S}-\mathrm{Hg}-\mathrm{S}$ bond angles are $90 \pm 3^{\circ}$ and $178 \pm 2^{\circ}$ for sulfur atoms in cis- or trans-position, 
respectively. We note, however, the increasing distortion of square geometry for mixed and hybrid clusters compared to a single $\mathrm{HgS}_{4}$ molecule, evidenced by variability of bond lengths and angles, i.e., $90.0 \pm 0.2^{\circ}\left(\mathrm{HgS}_{4}\right)$ vs. $90 \pm 3^{\circ}\left(\mathrm{Hg}_{2} \mathrm{~S}_{5}\right.$ or $\left.\mathrm{HgAsS}_{6}\right)$.

The $-\mathrm{S}-\mathrm{Hg}-\mathrm{S}-$ chain fragments are characterized by shorter bonds, $2.36 \pm 0.01 \AA$, and usual bond angles for chains, $\angle \mathrm{S}-\mathrm{Hg}-\mathrm{S}=176 \pm 3^{\circ}$. These results are consistent with those reported previously ${ }^{15}$ and diffraction data, Fig. $8(\mathrm{~b})$. The $\mathrm{AsS}_{3}$ pyramidal units show a distorted $\mathrm{C}_{3 \mathrm{v}}$ symmetry with similar As-S distances, $2.28 \AA$, but different angular parameters, $\angle \mathrm{S}-\mathrm{As}-\mathrm{S}=$ $97 \pm 7^{\circ}$. The full set of optimized geometry for DFT-relaxed clusters is given in Table 3 .

Table 3. Optimized geometry parameters (mercury-sulfur, $r\left(\mathrm{Hg}_{2 F^{-}} \mathrm{S}\right) / r\left(\mathrm{Hg}_{4 F^{-}} \mathrm{S}\right)$, and arsenic-sulfur, r(As-S), interatomic distances, and related bond angles) of isolated $\mathrm{HgS}_{4}{ }^{\mathrm{s}}$ mixed $\mathrm{Hg}_{2} \mathrm{~S}_{5}{ }_{5}, \mathrm{Hg}_{3} \mathrm{~S}_{6}{ }_{6}^{\mathrm{s}}$, $\mathrm{Hg}_{3} \mathrm{~S}_{8}{ }_{8}$, and hybrid $\mathrm{HgAsS}_{6}{ }^{\mathrm{S}}$ clusters used in DFT modelling of vibrational properties.

\begin{tabular}{|c|c|c|c|c|c|c|c|}
\hline & $\begin{array}{c}r\left(\mathrm{Hg}_{4 F}-\mathrm{S}\right) \\
(\AA)\end{array}$ & $\begin{array}{c}r\left(\mathrm{Hg}_{2 F}-\mathrm{S}\right) \\
(\AA)\end{array}$ & $\begin{array}{c}\angle \mathrm{S}-\mathrm{Hg}_{4 F}-\mathrm{S} \\
\quad(\mathrm{deg})\end{array}$ & $\begin{array}{c}\angle \mathrm{S}-\mathrm{Hg}_{2 F}-\mathrm{S} \\
(\mathrm{deg})\end{array}$ & $\begin{array}{c}r(\mathrm{As}-\mathrm{S}) \\
(\AA)\end{array}$ & $\begin{array}{c}\angle \mathrm{S}-\mathrm{As}-\mathrm{S} \\
(\mathrm{deg})\end{array}$ & $\begin{array}{c}\angle \mathrm{Hg}-\mathrm{S}-\mathrm{X}^{\#} \\
(\mathrm{deg})\end{array}$ \\
\hline $\mathrm{HgS}_{4}{ }^{\$}$ & 2.42 & - & $\begin{array}{c}90.0(2)^{\|} \\
179.4(2)^{\S}\end{array}$ & - & - & - & - \\
\hline $\mathrm{Hg}_{2} \mathrm{~S}_{5}{ }^{\$}$ & $2.43(1)$ & $2.36(1)$ & $\begin{array}{c}90(3)^{\|} \\
178(2)^{\S}\end{array}$ & 175.8 & - & - & 100.4 \\
\hline $\mathrm{Hg}_{3} \mathrm{~S}_{6}{ }^{\$}$ & $2.43(2)$ & $2.36(1)$ & $\begin{array}{c}90(3)^{\|} \\
176(3)^{\S}\end{array}$ & $176.5(7)$ & - & - & $101.7(11)$ \\
\hline $\mathrm{Hg}_{3} \mathrm{~S}_{8}{ }^{\$}$ & $2.43(1)$ & $2.37(2)$ & $\begin{array}{c}90(3)^{\|} \\
177(4)^{\S}\end{array}$ & $175.8(11)$ & - & - & 100.5 \\
\hline $\mathrm{HgAsS}_{6}{ }^{\$}$ & $2.43(2)$ & - & $\begin{array}{c}90(3)^{\|} \\
178(2)^{\S}\end{array}$ & - & 2.28 & $97(7)$ & 103.3 \\
\hline $\begin{array}{l}{ }^{\$} \text { The termi } \\
{ }^{*} \mathrm{X}=\mathrm{Hg} \text { or } \\
{ }^{\mathrm{S}} \text { atoms in } \\
{ }^{\S} \mathrm{S} \text { atoms in }\end{array}$ & $\begin{array}{l}1 \text { protons in } t \\
\text { is } \\
\text { is-position } \\
\text { rans-positic }\end{array}$ & e formula are & omitted & & & & \\
\hline
\end{tabular}


The tetrahedral instability of $\mathrm{HgS}_{4}$ molecules in DFT simulations is related to the "standard" $\mathrm{T}=0 \mathrm{~K}$ ground state of analyzed systems. As a result, it is consistent with thermodynamic stability range of high-temperature cubic $\beta-\mathrm{HgS}$, metastable below $344{ }^{\circ} \mathrm{C}$, in contrast to low-temperature trigonal cinnabar. A non-negligible distortion of $\mathrm{HgS}_{4}$ square geometry in mixed and hybrid clusters, Table 3, suggests a variety of 4-fold coordinated mercury local environments in the $\mathrm{HgS}-\mathrm{As}_{2} \mathrm{~S}_{3}$ glasses.

The calculated frequencies of the most intense Hg-S symmetric stretching modes in DFT Raman spectra of different 4-fold coordinated mercury species are red-shifted compared to analogous $\mathrm{A}_{1}$ modes in $\left(\mathrm{HgS}_{2 / 2}\right)_{m}$ chains and hybrid units, see Fig. 9, Fig. S4 (Supporting information) and Ref. [15]. For example, a red shift of $-24 \mathrm{~cm}^{-1}$ is observed between the $\mathrm{Hg}_{2} \mathrm{~S}_{3}$ oligomer and $\mathrm{Hg}_{2} \mathrm{~S}_{5}$ mixed unit. This finding correlates with experimental Raman results ${ }^{16-18}$ and a small but distinct red shift $\left(-9 \mathrm{~cm}^{-1}\right)$ between $\alpha-$ and $\beta-\mathrm{HgS}$, schematically shown in Fig. 9(b) by the dashed and dash-dotted lines, respectively. On the other hand, the observed blue shift $\Delta \omega=\omega_{D F T}-\omega_{c r}$ between the simulated DFT frequencies and crystal data, $+20 \mathrm{~cm}^{-1} \leq \Delta \omega \leq$ $+50 \mathrm{~cm}^{-1}$, is certainly related to enhanced intrachain/intra-fragment interactions in small clusters compared to bulk 1D $(\alpha-\mathrm{HgS})$ or 3D $(\beta-\mathrm{HgS})$ network, discussed in details previously. ${ }^{15}$ However, the calculated frequencies are in good agreement with experimental glass results, Fig. 9(b), extending the hypothesis of strong intra-fragment interactions to $\mathrm{Hg}$-related structural motifs in glasses.

The presence of $\mathrm{HgS}_{4 / 4}$ units in mercury thioarsenate glasses, evidenced by neutron and high-energy X-ray diffraction, is consistent with Raman data and DFT simulations. The Hg-S symmetric stretching modes of both two-fold and 4-fold coordinated mercury entities in glasses 
are overlapping and hardly distinguishable. Nevertheless, a small red shift in $\mathrm{A}_{1}$ stretching frequencies between the two species implies an increasing linewidth and peak position evolution with increasing HgS content. The two trends (a 40\% increase in FWHM and a systematic red shift of $-11 \mathrm{~cm}^{-1}$ ) are observed experimentally. ${ }^{15}$

Using DFT, we have also verified a possible implication of 3-fold coordinated mercury in the structural organization of the $\mathrm{HgS}-\mathrm{As}_{2} \mathrm{~S}_{3}$ glasses. The DFT modelling of a trigonal Hg-S cluster has shown its instability. Starting from the initial $\mathrm{HgS}_{3}$ pyramidal configuration with identical Hg-S distances of $2.40 \AA$ and S-Hg-S angles $\left(109^{\circ}\right)$, one of the three sulfur species is rapidly moving out from the central mercury atom, $3 \AA$ after 16 DFT steps (Fig. S5, Supporting information). The remaining $\mathrm{HgS}_{2}$ unit transforms into a typical $\mathrm{HgS}_{2 / 2}$ chain fragment, ${ }^{15} r\left(\mathrm{Hg}_{2 F}-\mathrm{S}\right)=2.37 \AA, \angle \mathrm{S}-\mathrm{Hg}-\mathrm{S} \approx 180^{\circ}$.

Characteristic features in RMC generated glass structure model. As expected, a good agreement has been found between the experimental and simulated neutron and X-ray total structure factors $S_{N}(Q)$ and $S_{X}(Q)$, Fig. 1, and the neutron pair distribution function $g_{N}(r)$ for the $x=0.4$ glass, Fig. S6 (Supporting information). A snapshot of the $58.26 \AA$ RMC simulation box with 7600 atoms $(\mathrm{Hg}, \mathrm{As}, \mathrm{S})$ corresponding to the $x=0.4$ glass chemical composition is shown in Fig. 10(a). Typical RMC generated configurations for $\left(\mathrm{HgS}_{2 / 2}\right)_{m}$ chain fragments, isolated and agglomerated $\mathrm{HgS}_{4 / 4}$ structural units are visualized in Fig. 10(b). The partial pair distribution functions $g_{i j}(r)$ are given in Fig. 11 and the bond angle distributions $(\angle \mathrm{S}-\mathrm{As}-\mathrm{S}$, $\angle \mathrm{As}-\mathrm{S}-\mathrm{As}, \angle \mathrm{S}-\mathrm{Hg}-\mathrm{S}$, and $\angle \mathrm{Hg}-\mathrm{S}-\mathrm{Hg}$ ) in Fig. 12.

The RMC generated 3D structural model for the $x=0.4$ glass reproduces well the results of direct $T_{N}(r)$ and $T_{X}(r)$ fitting. The majority of arsenic species $(94.8 \%)$ are three-fold 
coordinated. The fraction of 4 -fold coordinated mercury is $f_{\mathrm{Hg}}^{4 F}=0.16$ vs. $0.18 \pm 0.02$ for direct fitting, Fig. 8(a). The distribution of arsenic and mercury coordination numbers is given in Fig. S7 (Supporting information). It should be noted that in the RMC modelling we have assumed a bimodal distribution of mercury coordination centered at $N_{\mathrm{Hg}-\mathrm{S}}=2$ and $N_{\mathrm{Hg}-\mathrm{S}}=4$ and used the respective coordination constraints. A significant implication of 3-fold coordinated mercury was excluded based on (i) known crystallographic data for binary mercury sulfide, ternary and multicomponent mercury(II) thio-compounds of Group VA/15 (P, As, Sb), IVA/14 (Si, Ge, Sn) and IIIA/13 (Al, Ga, In), more than 100 references in the Inorganic Crystal Structure Database (http://icsd.fiz-karlsruhe.de). In all these compounds, the mercury coordination was found to be 2 and/or 4. (ii) Our DFT modelling of a 3-fold coordinated Hg-S cluster has also shown its instability (Fig. S5, Supporting information). In future experiments, a mercury-selective local probe, i.e., ${ }^{199} \mathrm{Hg}$ NMR, could be efficient to precise the mercury coordination in glasses.

Additional structural information is available from the detailed analysis of RMC configuration using the RINGS $^{57}$ and the connectivity analysis ${ }^{58}$ codes. The angular distribution functions and mercury connectivity are of primary importance.

Angular distributions. The bond angle distribution $B(\theta)$ is related to the number of bonds between angles of $\theta$ and $\theta+\Delta \theta$, and the number of angles available at angle $\theta$ is proportional to $\sin \theta \cdot{ }^{59}$ Consequently, it is appropriate to remove this effect by plotting the distribution $B(\theta) /$ $\sin \theta \cdot{ }^{59-61}$ It should also be noted that the number of angles becomes vanishingly small at $\theta \approx \pi$ and the high- $\theta$ part of $B(\theta) / \sin \theta$ appears to be noisy. 

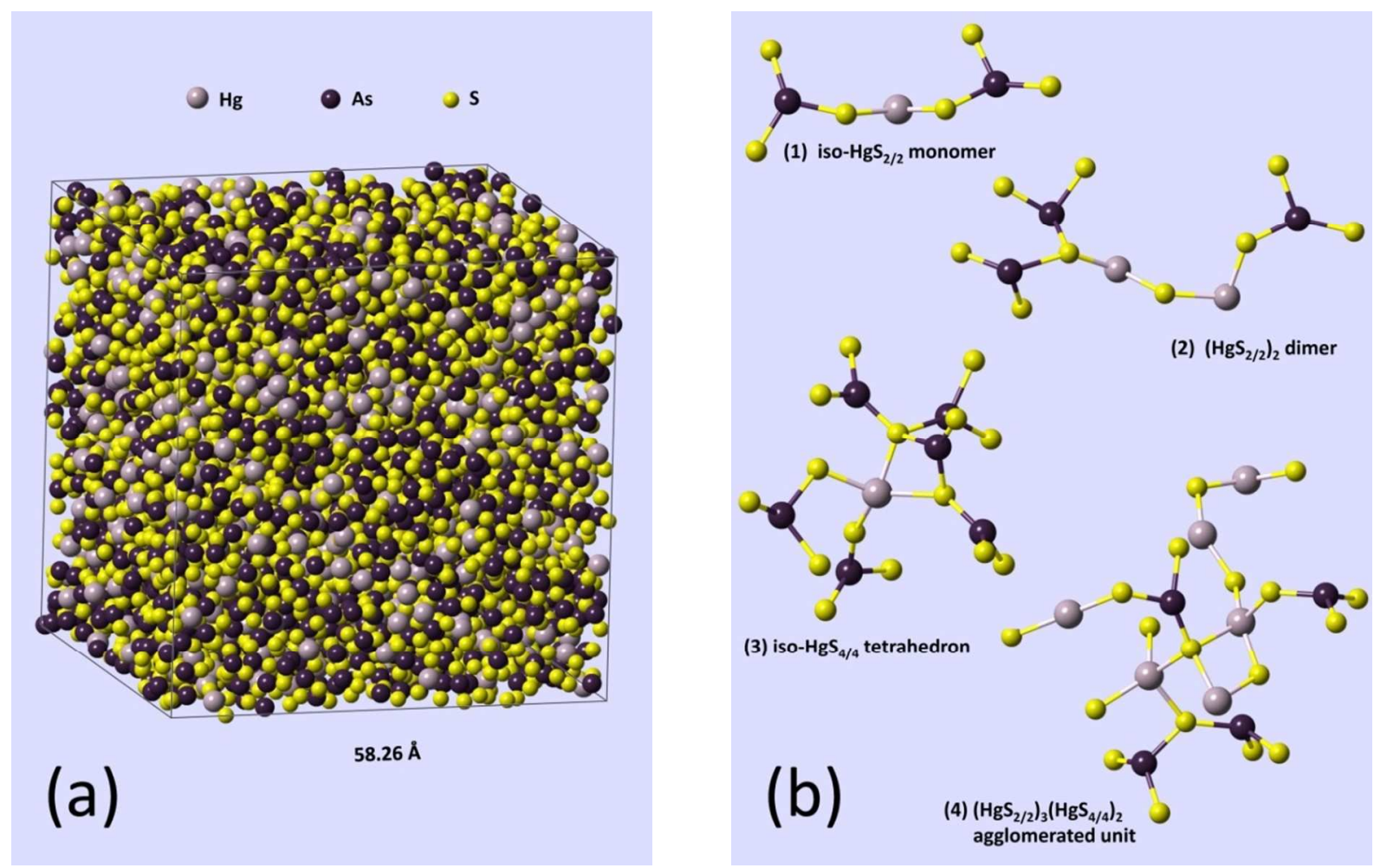

Figure 10. (a) A snapshot of the $58.26 \AA$ RMC simulation box with 7600 atoms (Hg, As, S) corresponding to the $x=0.4$ glass chemical composition; (b) typical RMC generated configurations: (1) isolated iso- $\mathrm{HgS}_{2 / 2}$ monomer (45.1\% of $\mathrm{Hg}$ sites) and (2) $\left(\mathrm{HgS}_{2 / 2}\right)_{2}$ dimer (14.8\%), (3) isolated iso- $\mathrm{HgS}_{4 / 4}$ (4.8\%) and (4) agglomerated $\left(\mathrm{HgS}_{2 / 2}\right)_{m}\left(\mathrm{HgS}_{4 / 4}\right)_{m}$, units (28.8\%). The remaining oligomeric chains $\left(\mathrm{HgS}_{2 / 2}\right)_{m}(5.0 \%), 2<m \leq 6$, and connected 4-fold coordinated $\left(\mathrm{HgS}_{4 / 4}\right)_{m}$, units $(1.5 \%)$ are not shown.

Arsenic-related bond angle distributions, Fig. 12(a) and (b), indicate that $\mathrm{AsS}_{3 / 2}$ pyramidal geometry is rather well preserved in the $x=0.4$ glass. Broad asymmetric features at $\approx 96^{\circ}$ for the two $B(\theta) / \sin \theta$ functions are consistent with characteristic bimodal values for monoclinic orpiment $c-\mathrm{As}_{2} \mathrm{~S}_{3}, \angle \mathrm{S}-\mathrm{As}-\mathrm{S}: 96 \pm 3^{\circ}(67 \%)$ and $104.5 \pm 0.5^{\circ}(33 \%) ; \angle \mathrm{As}-\mathrm{S}-\mathrm{As}: 88 \pm 4^{\circ}$ (33\%) and $102.4 \pm 1.5^{\circ}(67 \%){ }^{51}$ reflecting the $\mathrm{C}_{\mathrm{s}}$ symmetry of the $\mathrm{AsS}_{3 / 2}$ entities. As expected, trigonal units in the glass are more distorted in both intra-pyramidal geometry and interpyramidal connectivity. 


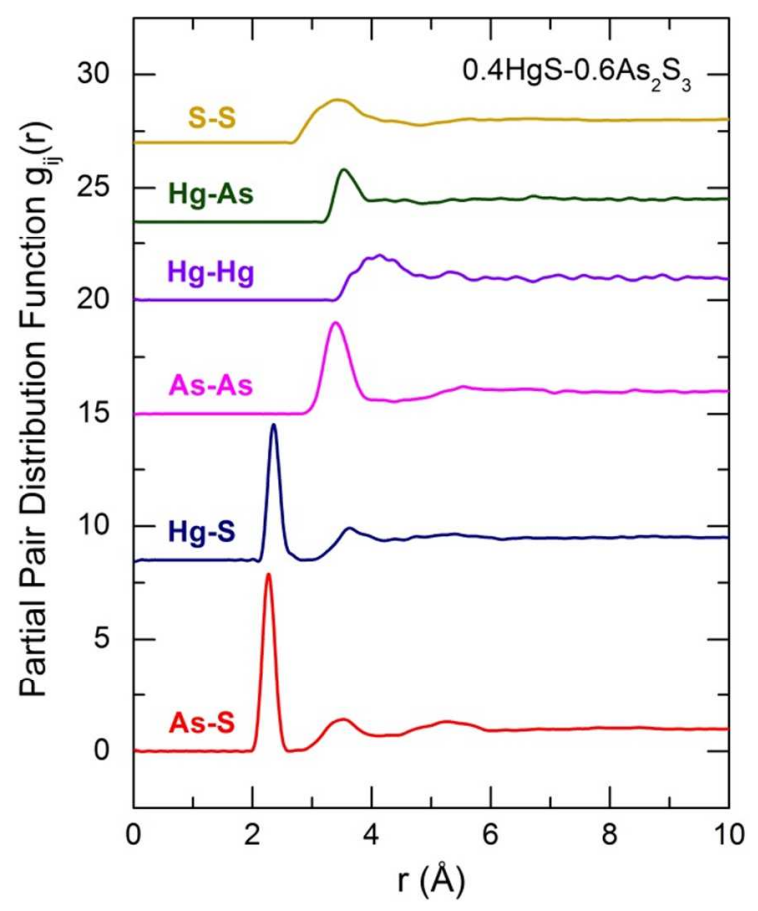

Figure 11. Simulated partial pair distribution functions $g_{i j}(r)$ for the $x=0.4$ glass.

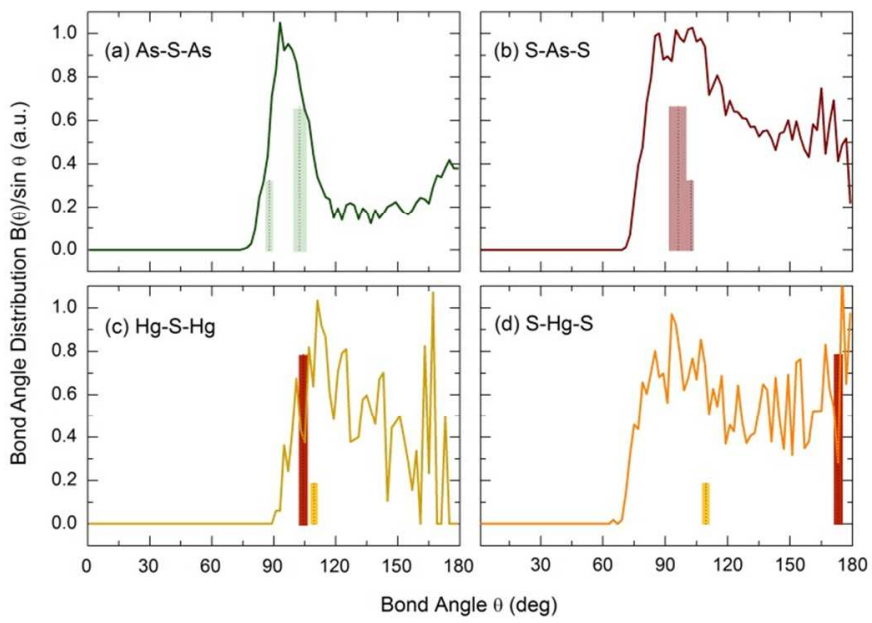

Figure 12. Simulated bond angle distributions $B(\theta) /$ $\sin \theta$ for the $x=0.4$ glass: (a) As-S-As, (b) S-As-S, (c) $\mathrm{Hg}-\mathrm{S}-\mathrm{Hg}$, and (d) S-Hg-S. The crystal values for monoclinic orpiment are shown by (a) green and (b) light brown bars; (c,d) the characteristic values for trigonal cinnabar are highlighted in red; the tetrahedral values for cubic metacinnabar in yellow. The bar height reflects the expected population of bonds for a given angle.

Mercury sulfide dimorphism in the glass network complicates interpretation of $\mathrm{Hg}$ related angular distributions, Fig. 12(c) and (d). Both two-fold and 4-fold coordinated mercury species seem to be highly distorted. For example, the $\mathrm{Hg}-\mathrm{S}$ chains in trigonal cinnabar are characterized by well-defined $\angle \mathrm{S}-\mathrm{Hg}-\mathrm{S}=173.1^{\circ}$ and $\angle \mathrm{Hg}-\mathrm{S}-\mathrm{Hg}=104.2^{\circ}$ bond angles $^{53}$ The fraction of nearly straight $\mathrm{S}-\mathrm{Hg}-\mathrm{S}$ angles is quite high in the $x=0.4$ glass, Fig. 12(d). Nevertheless, one observes an additional broad angular distribution with a maximum at $\approx \pi / 2$. The Hg-S-Hg angles are more regular. Their narrower distribution is centered at $\approx 110^{\circ}$, i.e., similar to the crystal value.

Small 4-fold coordinated mercury fraction $f_{\mathrm{Hg}}^{4 F}=0.16(\mathrm{RMC})$ or $0.18 \pm 0.02$ (direct fitting) makes hardly possible a comprehensive analysis of $\mathrm{HgS}_{4 / 4}$ tetrahedra using the entire simulation box. A separate examination has been carried out for four-fold coordinated Hg-S entities. Highly 
distorted $\mathrm{HgS}_{4 / 4}$ tetrahedra are mostly observed with a broad distribution of the tetrahedral S-Hg$\mathrm{S}$ angles, i.e., $108 \pm 17^{\circ}$ vs. $109.47^{\circ}$ for a regular tetrahedron, and of the Hg-S distances, e.g. $2.40 \pm 0.10 \AA$. Some of $\mathrm{HgS}_{4 / 4}$ units approach a square geometry with a distribution of the cisangles, ${ }^{62} 92 \pm 13^{\circ}$, centered on $\pi / 2$ and the trans-angles, $148 \pm 25^{\circ}$, similar to $\pi$. Some characteristic examples are shown in Fig. S8 (Supporting information). A large variety of 4-fold coordinated mercury species predicted by DFT is thus observed in RMC modelling.

Mercury connectivity. One half of $\mathrm{Hg}$-related entities are only connected to $\mathrm{AsS}_{3 / 2}$ pyramids, Fig. 10(b). Let's call them isolated units. The majority of isolated $\mathrm{Hg}-\mathrm{S}$ species $(45.1 \%$ of the total number of $\mathrm{Hg}$ sites) are two-fold coordinated chain monomers iso- $\mathrm{HgS}_{2 / 2}$. The fraction of isolated four-fold coordinated entities, iso- $\mathrm{HgS}_{4 / 4}$, is just $4.8 \%$ compared to $16 \%$ of $\mathrm{HgS}_{4 / 4}$ units present within the entire glass network. The iso- $\mathrm{HgS}_{2 / 2}$ and iso- $\mathrm{HgS}_{4 / 4}$ entities are distributed randomly over the network as shows the connectivity analysis.

Plotting the bound mercury fraction $F_{\mathrm{Hg}}(r)^{63}$ for the full RMC model containing $800 \mathrm{Hg}$ atoms as a function of $\mathrm{Hg}-\mathrm{Hg}$ separation distance, one observes that $95 \%$ of $\mathrm{Hg}-\mathrm{S}$ species are located within the $r(\mathrm{Hg}-\mathrm{Hg}) \leq 5.3 \AA$ range from each other (Fig. 13), consistent with the partial pair distribution function $g_{\mathrm{Hg}-\mathrm{Hg}}(r)$ (Fig. 11). The calculated value appears to be below the average random $\mathrm{Hg}-\mathrm{Hg}$ separation distance, $6.3 \AA$ in cubic or $7.8 \AA$ in spherical approximation, highlighted in Fig. 13 in red. This result was expected since one half of $\mathrm{Hg}-\mathrm{S}$ species are interconnected and the $\mathrm{Hg}-\mathrm{Hg}$ second neighbor distance is $4.1 \pm 0.5 \AA$. In contrast, $95 \%$ of isolated iso- $\mathrm{HgS}_{2 / 2}$ chain monomers reside within the $r(\mathrm{Hg}-\mathrm{Hg}) \leq 7.2 \AA$ range supporting a random distribution of isolated $\mathrm{Hg}-\mathrm{S}$ species. 


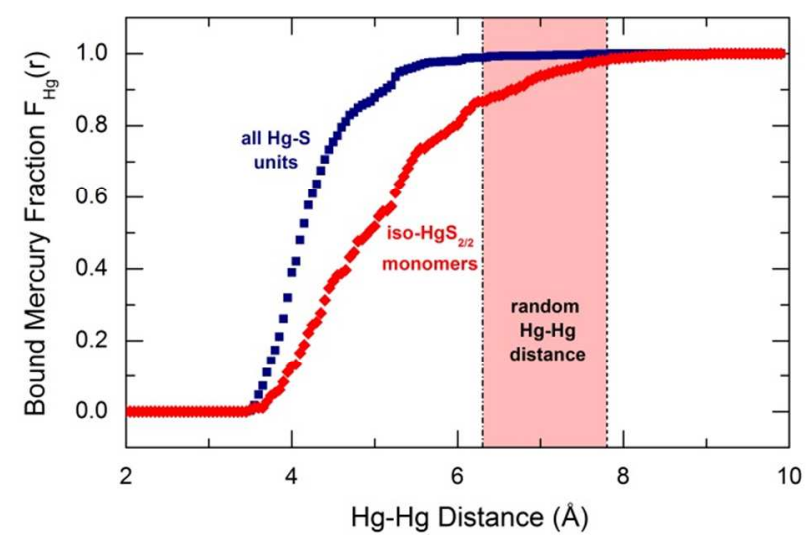

Figure 13. Bound mercury fraction $F_{\mathrm{Hg}}(r)^{63}$ for the RMC generated 3D structural model of the $x=0.4$ glass; blue squares: the entire simulation box containing $800 \mathrm{Hg}$ atoms, red diamonds: a partial reduced configuration containing 361 isolated $\mathrm{HgS}_{2 / 2}$ chain monomers. The derived random $\mathrm{Hg}-\mathrm{Hg}$ separation distance is highlighted in red spreading out between $6.3 \AA$ (cubic approximation) and $7.8 \AA$ (spherical approximation).

The results also imply that a subnetwork of isolated mercury species is slightly enriched in chain fragments and significantly depleted in 4-fold coordinated $\mathrm{Hg}$ entities (-40 \%) compared to the mercury speciation over the entire glass network. Consequently, the fraction of isolated $\mathrm{HgS}_{4 / 4}$ units for the $x=0.4$ glass appears to be similar to that in the Region 1 glasses, $f_{\mathrm{Hg}}^{4 F} \leq 0.1$ at $x<x_{0}$, Fig. $8(\mathrm{a})$.

The second half of mercury species form either connected chain fragments $\left(\mathrm{HgS}_{2 / 2}\right)_{m}$, where $m>1$, or mixed and agglomerated entities including $\mathrm{HgS}_{4 / 4}$ units, Fig. 10(b). The average chain length is rather small, $m \leq 6$, and the main chain-like fragments are dimers $(m=2,75 \%$ of the total number of $\left(\mathrm{HgS}_{2 / 2}\right)_{m}$ chains). Figure 14(b) shows the fractions of mercury involved in (i) two-fold coordinated $\mathrm{Hg}-\mathrm{S}$ chains, (ii) mixed and agglomerated $\left(\mathrm{HgS}_{2 / 2}\right)_{m}\left(\mathrm{HgS}_{4 / 4}\right)_{m}$, entities, and (iii) connected $\left(\mathrm{HgS}_{4 / 4}\right)_{m}$, units plotted as a function of the number of atoms $\ell$ in a connected structural fragment. For example, the number of atoms in a $\left(\mathrm{HgS}_{2 / 2}\right)_{3}$ trimer is $\ell=7$, identical to that in a $\left(\mathrm{HgS}_{2 / 2}\right)\left(\mathrm{HgS}_{4 / 4}\right)$ mixed unit. 


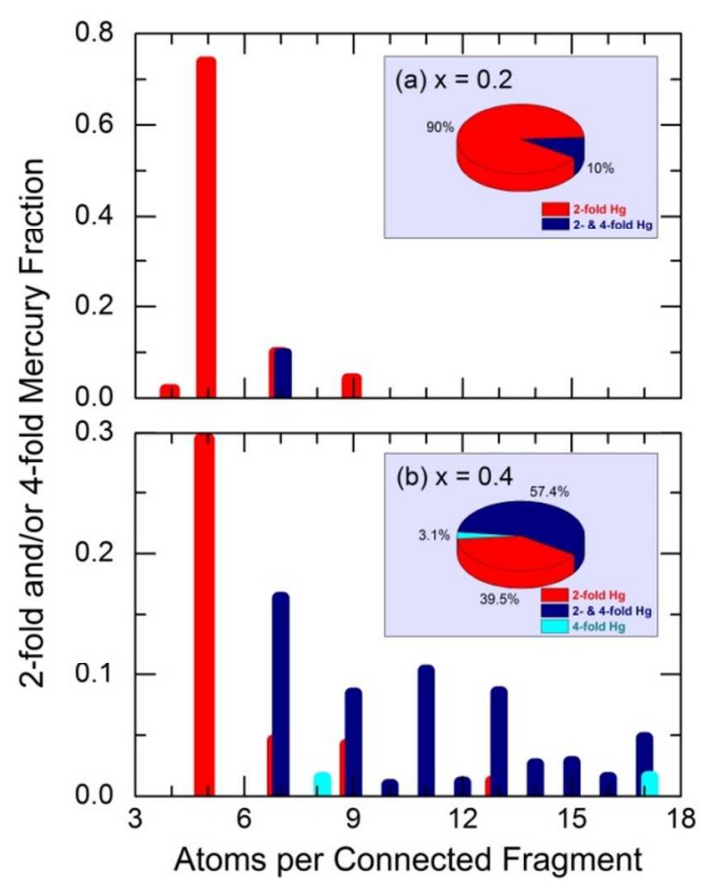

Figure 14. Size distribution of connected Hg-S entities of three types for the (a) $x=0.2$, and (b) $x=0.4$ glasses: (i) oligomeric chains $\left(\mathrm{HgS}_{2 / 2}\right)_{m}, 2 \leq m \leq 6$ (red); (ii) mixed agglomerated units $\left(\mathrm{HgS}_{2 / 2}\right)_{m}\left(\mathrm{HgS}_{4 / 4}\right)_{m}, 2 \leq m+m^{\prime} \leq 6$ (blue); (iii) connected tetrahedra $\left(\mathrm{HgS}_{4 / 4}\right)_{m}, m^{\prime}=2$ and 4 (cyan). The insets show the integrated $\mathrm{Hg}$ fraction for the three types of connected $\mathrm{Hg}-\mathrm{S}$ units.

The $\left(\mathrm{HgS}_{2 / 2}\right)_{2}$ dimers $(\ell=5)$ remain the highest single fraction of connected mercury; however, the population of other members of this family is small. The mixed and agglomerated Hg-S entities also contain up to $6\left(=m+m^{\prime}\right)$ interconnected $\mathrm{HgS}_{2 / 2}$ and $\mathrm{HgS}_{4 / 4}$ units but their size distribution is broader ensuring the next 5 positions in a population ranking. Finally, the minority species appear to be connected tetrahedral fragments.

The inset in Fig. 14(b) shows the summed Hg fraction for the three types of mercury connectivity. The mixed and agglomerated $\left(\mathrm{HgS}_{2 / 2}\right)_{m}\left(\mathrm{HgS}_{4 / 4}\right)_{m}$, entities appear to be the major species $(57.4 \%)$, whose population is by a factor of 1.5 higher than that of the $\left(\mathrm{HgS}_{2 / 2}\right)_{m}$ chains $(m>1,39.5 \%)$. A few connected $\left(\mathrm{HgS}_{4 / 4}\right)_{m}$, units are clearly outsiders $(3.1 \%)$. 
A preliminary RMC modelling of the $x=0.2$ glass (Region 1 ) shows a drastic difference in the mercury connectivity, Fig. 14(a), compared to the $x=0.4$ glass (Region 2). We note a larger fraction of isolated units iso- $\mathrm{HgS}_{2 / 2}$ and $i s o-\mathrm{HgS}_{4 / 4}, 76.5 \%(x=0.2)$ vs. $49.9 \%(x=0.4)$. The $\left(\mathrm{HgS}_{2 / 2}\right)_{2}$ dimers appear to be the major connected species while the fraction of short oligomeric chains $\left(\mathrm{HgS}_{2 / 2}\right)_{m}, 2<m \leq 4$, and $\left(\mathrm{HgS}_{2 / 2}\right)\left(\mathrm{HgS}_{4 / 4}\right)$ mixed units represents just one quarter of connected Hg-S entities. Further detailed analysis of RMC models for the entire HgS$\mathrm{As}_{2} \mathrm{~S}_{3}$ glass-forming domain will be published elsewhere.

Dual structural role of mercury and the nature of $\mathrm{HgS}$ dimorphism in glasses. Two composition domains in $(\mathrm{HgS})_{x}\left(\mathrm{As}_{2} \mathrm{~S}_{3}\right)_{1-x}$ glasses below (Region 1) and above $x_{0} \approx 0.3$ (Region 2), found using diffraction studies, are consistent with thermal and electronic transport properties: (i) the absence of crystallization peaks at $x \leq 0.3$ in a DSC experiment, and (ii) nonmonotonic changes of conductivity parameters with a distinct threshold at $x_{0} \approx 0.3$. $^{15}$ Crystallization-resistant HgS-poor thioarsenate glasses imply that two-fold coordinated mercury species forming $\left(\mathrm{HgS}_{2 / 2}\right)_{m}$ monomers $(m=1)$ and oligomeric chains $(m>1)$, the main Hg-related structural motif in Region 1, are acting as a network-former. The composition trends of the 1.3 $\AA^{-1}$ pre-peak (Fig. 4) also show that the $\mathrm{Hg}$-S chains do not modify significantly the $\mathrm{As}_{n} \mathrm{~S}_{n}$ ring size distribution and population. In other words, the chains easily co-exist with $\mathrm{AsS}_{3 / 2}$ pyramids leaving intact local and intermediate-range ordering in the $g-\mathrm{As}_{2} \mathrm{~S}_{3}$ host. The dielectric properties of chain-like mercury sulfide (red cinnabar $\alpha-\mathrm{HgS}$ is an electronic insulator, $E_{\mathrm{g}}=2.1 \mathrm{eV}^{64}$ ) explain a conductivity decrease and an activation energy increase for the Region 1 glasses. ${ }^{15}$

Tetrahedral $\mathrm{HgS}_{4 / 4}$ species behave as a network modifier. They are present in Region 1 but underlying structural hypothesis suggests a random distribution of $\mathrm{HgS}_{4 / 4}$ tetrahedra below 
$x_{0}$ when $f_{\mathrm{Hg}}^{4 F}<0.1$ and a formation of agglomerated $\left(\mathrm{HgS}_{2 / 2}\right)_{m}\left(\mathrm{HgS}_{4 / 4}\right)_{m}$, mixed clusters for the Region 2 glasses at $x>x_{0}$ and $f_{\mathrm{Hg}}^{4 F}>0.1$, Figs. 8 and 10. Similar agglomeration trend was observed for $\mathrm{A}_{y} \mathrm{Se}_{1-y}$ binary selenide glasses, where $\mathrm{A}=\mathrm{Si}, \mathrm{P}, \mathrm{Ge}$, or $\mathrm{As}^{65}$ Below $y_{0} \approx$ $0.10 \pm 0.02, \mathrm{ASe}_{k / 2}$ structural units $(k=4$ for $\mathrm{Si}$ or $\mathrm{Ge}$, and $k=3$ for $\mathrm{P}$ or As) are distributed randomly within chain-like selenium network but start forming interconnected A-related subnetwork above $y_{0}$. It should also be noted that the $\mathrm{HgS}$ molar concentration $x_{0}=0.30$ corresponds to the $\mathrm{Hg}$ atomic concentration $y_{0}=0.073$.

The rigid $\mathrm{HgS}_{4 / 4}$ tetrahedral fragments are hardly compatible with the hybrid chain/pyramidal network of the Region 1 glasses and crystallization attempts intensify with increasing $x>x_{0}$ (Fig. 3 in Ref. [15]). The $\mathrm{HgS}_{4 / 4}$ agglomeration also leads to a fragmentation of the glassy host. A rapid decrease of the $A_{0 \mathrm{~A}}(x)$ amplitude with simultaneous increase of $Q_{0 \mathrm{~A}}(x)$ implies a decreasing population of the $\mathrm{As}_{n} \mathrm{~S}_{n}$ rings and their diminished size. In contrast, the $\left(\mathrm{HgS}_{2 / 2}\right)_{m}$ monomers and oligomeric chains are less affected by tetrahedral $\mathrm{HgS}_{4 / 4}$ species. Their population just stops increasing at $\mathrm{x}>x_{0}$ (Fig. 4) but the intrachain angular distribution, affecting $Q_{0 \mathrm{~B}}(x)$, remains essentially intact.

The increasing population of agglomerated $\left(\mathrm{HgS}_{2 / 2}\right)_{m}\left(\mathrm{HgS}_{4 / 4}\right)_{m}$, mixed subnetwork and increasing tetrahedral $\mathrm{HgS}_{4 / 4}$ fraction changes the electronic properties. The conductivity starts increasing with corresponding decrease of the activation energy and optical gap (Fig. 6 in Ref. [15]) consistent with semiconducting properties of black cubic metacinnabar $\beta-\mathrm{HgS}\left(E_{\mathrm{g}}=0.4\right.$ $\mathrm{eV}){ }^{66}$

The question arises what is the reason of mercury sulfide dimorphism in glasses. Taking into account different thermal stability of trigonal cinnabar $\alpha-\mathrm{HgS}$ (stable below $344{ }^{\circ} \mathrm{C}$ ) and 
high-temperature cubic metacinnabar $\beta-\mathrm{HgS}$, one assumes that in the high-temperature melt mercury species exist as tetrahedral units $\mathrm{HgS}_{4 / 4}$ (no structural information is available for liquid $\mathrm{HgS}$ ). Quenching the $\mathrm{HgS}-\mathrm{As}_{2} \mathrm{~S}_{3}$ glass-forming melt, $\mathrm{HgS}_{4 / 4}$ tetrahedra are entirely or partially transformed into $\left(\mathrm{HgS}_{2 / 2}\right)_{m}$ chain fragments. The mercury transformation on cooling implies a significant distortion of both two-fold and 4-fold coordinated mercury species observed in RMC modelling and predicted by DFT simulations. The transformation rate seems to be dependent on stoichiometry relations $\mathrm{HgS} / \mathrm{As}_{2} \mathrm{~S}_{3}=x /(1-x)$ and increases with decreasing $x$. Metastable at room temperature, frozen $\beta-\mathrm{HgS}$, observed for the $x=0.5$ neutron sample, is consistent with this hypothesis. Further studies of $\mathrm{HgS}-\mathrm{As}_{2} \mathrm{~S}_{3}$ liquids are necessary to elucidate the nature of mercury sulfide dimorphism in glasses.

\section{CONCLUSIONS}

Pulsed neutron and high-energy X-ray diffraction of mercury thioarsenate glasses $(\mathrm{HgS})_{\mathrm{x}}\left(\mathrm{As}_{2} \mathrm{~S}_{3}\right)_{1-x}, 0.0 \leq x \leq 0.5$, combined with DFT simulation of four-fold mercury species and RMC modelling of high-resolution diffraction data were used to unveil short- and intermediaterange ordering of these exciting vitreous materials of practical importance. Mercury sulfide appears to be dimorphous over the investigated composition range. The main structural motif consists of $\left(\mathrm{HgS}_{2 / 2}\right)_{m}$ monomers $(m=1)$ and oligomeric chains $(2 \leq m \leq 6)$ forming a hybrid $\mathrm{Hg}$ $\mathrm{S}$ chain/As-S pyramidal network. The two-fold coordinated mercury is thus a network former. The population of 4-fold coordinated $\mathrm{HgS}_{4 / 4}$ minorities increases with $x$ but even at the glassforming limit, $x=0.5$, the fraction of four-fold coordinated mercury is below $50 \%$, i.e., $f_{\mathrm{Hg}}^{4 F} \approx$ 0.3. The highly distorted tetrahedral mercury species behave as a network modifier. Two 
composition domains have been found in the $\mathrm{HgS}-\mathrm{As}_{2} \mathrm{~S}_{3}$ glasses with a threshold concentration $x_{0} \approx 0.3$. In mercury-poor glasses (Region $1, x<x_{0}$ ), the $\mathrm{HgS}_{4 / 4}$ units seem to be distributed randomly in the hybrid network and do not affect structural, thermal or electronic properties. An agglomerated mixed $\left(\mathrm{HgS}_{2 / 2}\right)_{m}\left(\mathrm{HgS}_{4 / 4}\right)_{m}$, subnetwork is formed in $\mathrm{HgS}$-rich vitreous alloys (Region 2, $x>x_{0}, f_{\mathrm{Hg}}^{4 F}>0.1$ ), leading to a fragmentation of the host network, reduced thermal stability and crystallization as well as changes in electronic properties. The nature of mercury sulfide dimorphism in glasses appears to be related to a polyamorphic transformation during glass synthesis and quenching. Further studies of high-temperature $\mathrm{HgS}-\mathrm{As}_{2} \mathrm{~S}_{3}$ liquids will give a detailed and definitive answer.

\section{ASSOCIATED CONTENT}

\section{Supporting Information}

DSC traces and small-angle neutron scattering intensity for homogeneous $(\mathrm{HgS})_{0.4}\left(\mathrm{As}_{2} \mathrm{~S}_{3}\right)_{0.6}$ and phase-separated $\mathrm{AsS}_{5}$ glasses (Figure $\mathrm{S} 1$ )

The low- $Q$ pre-peaks isolated from the difference structure factors $\Delta S(Q)$ without As-Hg or $\mathrm{Hg}-\mathrm{Hg}$ correlations for the $x=0.4$ glass (Figure $\mathrm{S} 2$ )

DFT transformation of an $\mathrm{HgS}_{4}$ tetrahedron into an $\mathrm{HgS}_{4}$ square (Figure S3)

DFT Raman spectra of Hg-As-S hybrid clusters with two-fold and 4-fold coordinated mercury (Figure S4)

The Supporting Information is available free of charge via the Internet at http://pubs.acs.org.

Instability of an $\mathrm{HgS}_{3}$ pyramidal unit during DFT geometry optimization (Figure S5) 


\author{
Experimental and simulated neutron pair distribution function for the $0.4 \mathrm{HgS}-0.6 \mathrm{As}_{2} \mathrm{~S}_{3}$ \\ glass (Figure S6)
}

Distribution of $\mathrm{Hg}-\mathrm{S}$ and As-S coordination numbers in the RMC model of $0.4 \mathrm{HgS}-$ $0.6 \mathrm{As}_{2} \mathrm{~S}_{3}$ glass (Figure $\mathrm{S} 7$ )

Characteristic distorted $\mathrm{HgS}_{4 / 4}$ units in the 7600 atoms RMC model (Figure S8)

\author{
AUTHOR INFORMATION \\ Corresponding Author \\ *E-mail: bychkov@univ-littoral.fr \\ *Telephone: $+33-328-658250$
}

\title{
Author Contributions
}

The manuscript was written through contributions of all authors. All authors have given approval to the final version of the manuscript.

\section{Notes}

The authors declare no competing financial interest.

\section{ACKNOWLEDGMENT}

This work was supported by Agence Nationale de la Recherche (ANR, France) under grant No. ANR-15-ASTR-0016-01. Research conducted at ORNL's Spallation Neutron Source was sponsored by the Scientific User Facilities Division, Office of Basic Energy Sciences, U.S. Department of Energy. Experiments at the ISIS Pulsed Neutron and Muon Source were supported by a beamtime allocation (RB1510269) from the Science and Technology Facilities 
Council. Work at the Advanced Photon Source, Argonne National Laboratory was supported in part by the Office of Basic Energy Sciences, U.S. Department of Energy under contract No. DEAC02-06CH1135. 


\section{REFERENCES}

(1) Mishima, O.; Calvert L. D.; Whalley R. 'Melting Ice' I at $77 \mathrm{~K}$ and $10 \mathrm{kbar}$ : A New Method of Making Amorphous Solids. Nature 1984, 310, 393-395.

(2) Poole, P. H.; Grande, T.; Angell C. A.; McMillan P. F. Polymorphic Phase Transitions in Liquids and Glasses. Science 1997, 275, 322-323.

(3) Katayama, Y.; Mizutani, T.; Utsumi, W.; Shimomura, O.; Yamakata, M.; Funakoshi, K. A First-Order Liquid-Liquid Phase Transition in Phosphorus. Nature 2000, 403, 170-173.

(4) Tulk, C. A.; Benmore, C. J.; Urquidi, J.; Klug, D. D.; Neuefeind, J.; Tomberli, B.; Egelstaff, P. A. Structural Studies of Several Distinct Metastable Forms of Amorphous Ice. Science 2002, 297, 1320-1323.

(5) McMillan, P. F. Polyamorphic Transformations in Liquids and Glasses. J. Mater. Chem. 2004, 14, 1506-1512.

(6) Greaves, G. N.; Wilding, M. C.; Fearn, S.; Langstaff, D.; Kargl, F.; Cox, S.; Van, Q. V.; Majérus, O.; Benmore, C. J.; Weber, R.; et al.; Detection of First-Order Liquid/Liquid Phase Transitions in Yttrium Oxide-Aluminum Oxide Melts. Science 2008, 322, 566-570.

(7) Barnes, A. C.; Skinner, L. B.; Salmon, P. S.; Bytchkov, A.; Pozdnyakova, I.; Farmer, T. O.; Fischer, H. E. Liquid-Liquid Phase Transition in Supercooled Yttria-Alumina. Phys. Rev. Lett. 2009, 103, 225702.

(8) Stanley, H. E. (Ed.), Liquid Polymorphism, Advances in Chemical Physics, Vol. 152; Wiley: Hoboken, N.J., 2013.

(9) Brazhkin, V. V.; Gavrilyuk, A. G.; Lyapin, A. G.; Timofeev, Yu. A.; Katayama, Y.; Kohara, S. AsS: Bulk Inorganic Molecular-Based Chalcogenide Glass. Appl. Phys. Lett. 2007, $91,031912$. 
(10) Brazhkin, V. V.; Katayama, Y.; Kondrin, M. V.; Hattori, T.; Lyapin, A. G.; Saitoh, H. AsS Melt under Pressure: One Substance, Three Liquids. Phys. Rev. Lett. 2008, 100, 145701.

(11) Riley, M. R.; Lucas, P.; Le Coq, D.; Juncker, C.; Boesewetter, D. E.; Collier, J. L.; De Rosa, D. M.; Katterman, M. E.; Boussard-Plédel, C.; Bureau, B. Lung Cell Fiber Evanescent Wave Spectroscopic Biosensing of Inhalation Health Hazards. Biotechnol. Bioeng. 2006, 95, 599-612.

(12) Wilhelm, A. A.; Boussard-Plédel, C.; Coulombier, Q.; Lucas, J.; Bureau, B.; Lucas, P. Development of Far-Infrared-Transmitting Te Based Glasses Suitable for Carbon Dioxide Detection and Space Optics. Adv. Mater. 2007, 19, 3796-3800.

(13) Beichman, C.; Gomez, G.; Lo, M.; Masdemont, J.; Romans, L. Searching for Life with the Terrestrial Planet Finder: Lagrange Point Options for a Formation Flying Interferometer. Adv. Space Res. 2004, 34, 637-644.

(14) Joiner, J.; Yoshida, Y.; Vasilkov, A. P.; Yoshida, Y.; Corp, L. A.; Middleton, E. M. First Observations of Global and Seasonal Terrestrial Chlorophyll Fluorescence from Space. Biogeosciences 2011, 8, 637-651.

(15) Kassem, M.; Khaoulani, S.; Cuisset, A.; Le Coq, D.; Masselin P.; Bychkov, E. Mercury Thioarsenate Glasses: A Hybrid Chain/Pyramidal Network. RSC Adv. 2014, 4, 49236-49246.

(16) Zallen, R.; Lucovsky, G.; Taylor, W.; Pinczuk, A.; Burstein, E. Lattice Vibrations in Trigonal HgS. Phys. Rev. B: Condens. Matter Mater. Phys. 1970, 1, 4058-4070.

(17) Imaino, W.; Simpson, C. T.; Becker, W. M.; Ramdas, A. K. Resonant Raman Effect in Cinnabar. Phys. Rev. B: Condens. Matter Mater. Phys. 1980, 21, 634-642.

(18) Szuszkiewicz, W.; Witkowska, B.; Jouanne, M.; Balkanski, M. Raman Spectroscopy of Cubic $\mathrm{Hg}_{1-x} \mathrm{Fe}_{x}$ S. Mater. Sci. Forum 1995, 182-184, 711-714. 
(19) Sears, V. F. Neutron Scattering Lengths and Cross Sections. Neutron News 1992, 3, 2637.

(20) Benmore, C. J.; Soper, A. K. A Guide to Performing Experiments on the Small Angle Neutron Diffractometer for Amorphous and Liquid Samples at ISIS, Rutherford-Appleton Laboratory Report, 1998.

(21) Hannon, A. C. Results on Disordered Materials from the GEneral Materials Diffractometer, GEM, at ISIS. Nucl. Instr. Methods A 2005, 551, 88-107.

(22) Hannon, A. C.; Howells, W. S.; Soper, A. K. ATLAS: A Suite of Programs for the Analysis of Time-of-Flight Neutron Diffraction Data from Liquid and Amorphous Samples. Inst. Phys. Conf. Ser. 1990, 107, 193-211.

(23) Neuefeind, J.; Feygenson, M.; Carruth, J.; Hoffmann, R.; Chipley, K. K. The Nanoscale Ordered MAterials Diffractometer NOMAD at the Spallation Neutron Source SNS. Nucl. Instr. Methods B 2012, 287, 68-75.

(24) Bytchkov, A.; Cuello, G. J.; Kohara, S.; Benmore, C. J.; Price, D. L.; Bychkov, E. Unraveling the Atomic Structure of Ge-rich Sulfide Glasses. Phys. Chem. Chem. Phys. 2013, 15, 8487-8494.

(25) Alderman, O. L. G.; Liška, M.; Macháček, J.; Benmore, C. J.; Lin, A.; Tamalonis, A.; Weber, J. K. R. Temperature-Driven Structural Transitions in Molten Sodium Borates $\mathrm{Na}_{2} \mathrm{O}-\mathrm{B}_{2} \mathrm{O}_{3}$ : X-ray Diffraction, Thermodynamic Modeling, and Implications for Topological Constraint Theory. J. Phys. Chem. C 2016, 120, 553-560.

(26) Hammersley, A. P.; Svensson, S. O.; Hanfland, M.; Fitch, A. N.; Häusermann, D. TwoDimensional Detector Software: From Real Detector to Idealised Image or Two-Theta Scan. High Pressure Res. 1996, 14, 235-248. 
(27) Wagner, C. N. J. Direct Methods for the Determination of Atomic-Scale Structure of Amorphous Solids (X-ray, Electron, and Neutron Scattering). J. Non-Cryst. Solids 1978, 31, 140.

(28) Skinner, L. B.; Benmore, C. J.; Parise, J. B. Area Detector Corrections for High Quality Synchrotron X-ray Structure Factor Measurements. Nuclear Instr. Methods A 2012, 662, 61-70.

(29) Frisch, M. J.; Trucks, G. W.; Schlegel, H. B.; Scuseria, G. E.; Robb, M. A.; Cheeseman, J. R.; Scalmani, G.; Barone, V.; Mennucci, B.; Petersson, G. A.; et al. Gaussian 09, Revision D.01, Gaussian, Inc., Wallingford, CT, 2009.

(30) Cuisset, A.; Hindle, F.; Laureyns, J.; Bychkov, E. Structural Analysis of $x \mathrm{CsCl}(1-x) \mathrm{Ga}_{2} \mathrm{~S}_{3}$ Glasses by Means of DFT Calculations and Raman Spectroscopy. J. Raman Spectrosc. 2010, 41, 1050-1058.

(31) Becke, A. D. Density-Functional Thermochemistry. III. The Role of Exact Exchange. J. Chem. Phys. 1993, 98, 5648-5653.

(32) Lee, C.; Yang, W.; Parr, R. G. Development of the Colle-Salvetti Correlation-Energy Formula into a Functional of the Electron Density. Phys. Rev. B: Condens. Matter Mater. Phys. 1988, 37, 785-789.

(33) Feller, D. The Role of Databases in Support of Computational Chemistry Calculations. J. Comput. Chem. 1996, 17, 1571-1586.

(34) Peterson, K. A.; Figgen, D.; Goll, E.; Stoll, H.; Dolg, M. Systematically Convergent Basis Sets with Relativistic Pseudopotentials. II. Small-Core Pseudopotentials and Correlation Consistent Basis Sets for the Post-d Group 16-18 Elements. J. Chem. Phys. 2003, 119, 11113. 
(35) Gereben, O.; Jóvári, P.; Temleitner, L.; Pusztai, L. A New Version of the RMC++ Reverse Monte Carlo Programme, Aimed at Investigating the Structure of Covalent Glasses. $J$. Optoelectr. Adv. Mater. 2007, 9, 3021-3027.

(36) Gereben, O.; Pusztai, L. Extension of the Invariant Environment Refinement Technique

+ Reverse Monte Carlo Method of Structural Modelling for Interpreting Experimental Structure Factors: the Cases of Amorphous Silicon, Phosphorus, and Liquid Argon. J. Chem. Phys. 2011, $135,084111$.

(37) McGreevy, R. L.; Pusztai, L. Reverse Monte Carlo Simulation: A New Technique for the Determination of Disordered Structures. Mol. Simul. 1988, 1, 359-367.

(38) Gereben, O.; Pusztai, L. Structure of Amorphous Semiconductors: Reverse Monte Carlo Studies on a-C, a-Si and a-Ge. Phys. Rev. B: Condens. Matter Mater. Phys. 1994, 50, 1413614143.

(39) McGreevy, R. L. Reverse Monte Carlo Modelling. J. Phys. Condens. Matter 2001, 13, R877-R913.

(40) Cliffe, M. J.; Dove, M. T.; Drabold, D. A.; Goodwin, A. L. Structure Determination of Disordered Materials from Diffraction Data. Phys. Rev. Lett. 2010, 104, 125501.

(41) Tsuchihashi, S.; Kawamoto, Y. Properties and Structure of Glasses in the System As-S. J. Non-Cryst. Solids 1971, 5, 286-305.

(42) Leadbetter, A. J.; Apling, A. J. Diffraction Studies of Glass Structure. V. The Structure of Some Arsenic Chalcogenide Glasses. J. Non-Cryst. Solids 1974, 15, 250-268.

(43) Zhou, W.; Sayers, D. E.; Paesler, M. A.; Boucher-Fabre, B.; Ma, Q.; Raoux, D. Structure and Photoinduced Structural Changes in a- $\mathrm{As}_{2} \mathrm{~S}_{3}$ Films: A Study by Differential Anomalous Xray Scattering. Phys. Rev. B: Condens. Matter Mater. Phys. 1993, 47, 686-694. 
(44) Iwadate, Y.; Hattori, T.; Nishiyama, S.; Fukushima, K.; Mochizuki, Y.; Misawa, M.; Fukunaga, T. Pulsed Neutron Diffraction Study of the Short Range Structure in Amorphous Arsenic Chalcogenides. J. Phys. Chem. Solids 1999, 60, 1447-1451.

(45) Barney, E. R.; Abdel-Moneim, N. S.; Towey, J. J.; Titman, J.; McCarthy, J. E.; Bookey, H. T.; Kar, A.; Furnissa, D.; Seddon, A. B. Correlating Structure with Non-Linear Optical Properties in $x \mathrm{As}_{40} \mathrm{Se}_{60} \cdot(1-x) \mathrm{As}_{40} \mathrm{~S}_{60}$ glasses. Phys. Chem. Chem. Phys. 2015, 17, 6314-6327.

(46) Bychkov, E.; Price, D. L. Neutron Diffraction Studies of $\mathrm{Ag}_{2} \mathrm{~S}-\mathrm{As}_{2} \mathrm{~S}_{3}$ Glasses in the Percolation and Modifier-Controlled Domains. Solid State Ionics 2000, 136-137, 1041-1048.

(47) Bychkov, E.; Miloshova, M.; Price, D. L.; Benmore, C. J.; Lorriaux, A. Short, Intermediate and Mesoscopic Range Order in Sulfur-Rich Binary Glasses. J. Non-Cryst. Solids 2006, 352, 63-70.

(48) Moss S. C.; Price, D. L. Random Packing of Structural Units and the First Sharp Diffraction Peak in Glasses. In Physics of Disordered Materials; Adler, D., Fritzsche, H., Ovshinsky, S. R., Eds.; Plenum: New York, 1985; pp. 77-95.

(49) Elliott, S. R. Medium-Range Structural Order in Covalent Amorphous Solids. Nature 1991, 354, 445-452.

(50) Salmon, P. S. Real Space Manifestation of the First Sharp Diffraction Peak in the Structure Factor of Liquid and Glassy Materials. Proc. R. Soc. London, Ser. A 1994, 445, 351365.

(51) Mullen, D. J. E.; Nowacki, W. Refinement of the Crystal Structures of Realgar, AsS and Orpiment, $\mathrm{As}_{2} \mathrm{~S}_{3}$. Z. Kristallogr. 1972, 136, 48-65. 
(52) Simdyankin, S. I.; Elliott, S. R.; Hajnal, Z.; Niehaus, T. A.; Frauenheim, Th. Simulation of Physical Properties of the Chalcogenide Glass $\mathrm{As}_{2} \mathrm{~S}_{3}$ using a Density-Functional-Based TightBinding Method. Phys. Rev. B: Condens. Matter Mater. Phys. 2004, 69, 144202.

(53) Schleid, T.; Lauxmann, P.; Schneck, C. Roentgenographische Einkristalluntersuchungen an alpha-HgS (Zinnober). Z. Kristallogr. 1999, 16, 95.

(54) Rodic, D.; Spasojevic, V.; Bajorek, A.; Onnerud, P. Similarity of Structure Properties of $\mathrm{Hg}_{1-x} \mathrm{Mn}_{x} \mathrm{~S}$ and $\mathrm{Cd}_{1-x} \mathrm{Mn}_{x} \mathrm{~S}$ (Structure Properties of HgMnS and CdMnS). J. Magn. Magn. Mater. 1996, 152, 159-164.

(55) Lorch, E. Neutron Diffraction by Germania, Silica and Radiation-Damaged Silica Glasses. J. Phys. C: Solid State Phys. 1969, 2, 229-237.

(56) Susman, S.; Volin, K. J.; Montague, D. G.; Price, D. L. The Structure of Vitreous and Liquid GeSe 2 : A Neutron Diffraction Study. J. Non-Cryst. Solids 1990, 125, 168-180.

(57) Le Roux, S.; Jund, P. Ring Statistics Analysis of Topological Networks: New Approach and Application to Amorphous $\mathrm{GeS}_{2}$ and $\mathrm{SiO}_{2}$ Systems. Comput. Mater. Sci. 2010, 49, 70-83.

(58) Kohara, S.; Ohno, H.; Tabaka, M.; Usuki, T.; Morita, H.; Suzuya, K.; Akola, J.; Pusztai, L. Lead Silicate Glasses: Binary Network-Former Glasses with Large Amounts of Free Volume. Phys. Rev. B: Condens. Matter Mater. Phys. 2010, 82, 134209.

(59) Tucker, M. G.; Keen, D. A.; Evans, J. S. O.; Dove, M. T. Local Structure in $\mathrm{ZrW}_{2} \mathrm{O}_{8}$ from Neutron Total Scattering. J. Phys.: Condens. Matter 2007, 19, 335215.

(60) Zeidler, A.; Salmon, P. S.; Martin, R. A.; Usuki, T.; Mason, P. E.; Cuello, G. J.; Kohara, S.; Fischer, H. E. Structure of Liquid and Glassy $\mathrm{ZnCl}_{2}$. Phys. Rev. B: Condens. Matter Mater. Phys. 2010, 82, 104208. 
(61) Bouzid, A.; Pizzey, K. J.; Zeidler, A.; Ori, G.; Boero, M.; Massobrio, C.; Klotz, S.; Fischer, H. E.; Bull, C. L.; Salmon, P. S. Pressure-Induced Structural Changes in the NetworkForming Isostatic Glass GeSe 4 : An Investigation by Neutron Diffraction and First-Principles Molecular Dynamics. Phys. Rev. B: Condens. Matter Mater. Phys. 2016, 93, 014202.

(62) The $\angle \mathrm{S}-\mathrm{Hg}-\mathrm{S}$ Angles with $\mathrm{S}$ Atoms is Cis-position for a $\mathrm{HgS}_{4}$ Square are called for Short 'Cis-angles' and those with S Species in Trans-position as 'Trans-angles'. The Cis-angles are equal to $\pi / 2$ and the Trans-angles are $\pi$ for a Square of $D_{4 h}$ Symmetry, see also Fig. 9(a) and Fig. S3 (Supporting information).

(63) The Bound Mercury Fraction $F_{\mathrm{Hg}}(r)$ is Defined as a Fraction of Mercury Species having at Least one Hg Nearest or Distant Neighbor at the Distance $r$.

(64) Berger, L. I. Semiconductor Materials, CRC press: New York, 1997.

(65) Bychkov, E.; Benmore, C. J.; Price, D. L. Compositional Changes of the First Sharp Diffraction Peak in Binary Selenide Glasses. Phys. Rev. B: Condens. Matter Mater. Phys. 2005, $72,172107$.

(66) Mahapatra, A. K., Dash, A. K. $\alpha$-HgS Nanocrystals: Synthesis, Structure and Optical Properties. Physica E 2006, 35, 9-15. 


\section{The TOC Graphic}

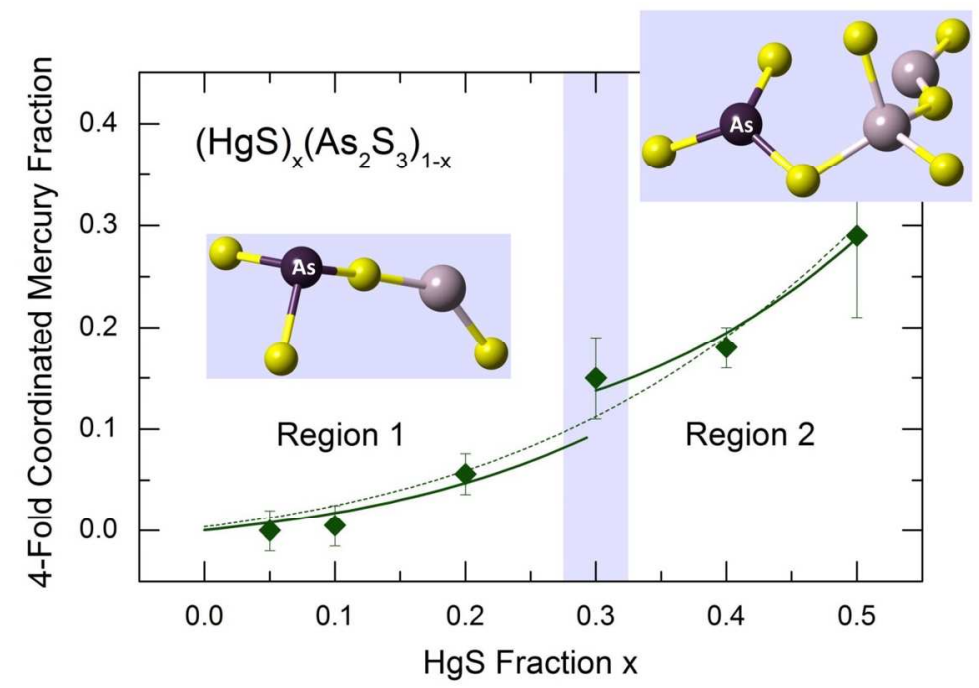

29

30

31

32

33

34

35

36

37

38

39

40

41

42

43

44

45

46

47

48

49

50

51

52

53

54

55

56

57

58

59

60 